\title{
EP3R-Expressing Glutamatergic Preoptic Neurons Mediate Inflammatory Fever
}

\author{
№talia L.S. Machado, ${ }^{1}$ Sathyajit S. Bandaru, ${ }^{1}$ SStephen B.G. Abbott, ${ }^{2}$ and $\mathbb{C C l i f f o r d ~ B . ~ S a p e r ~}^{1}$ \\ ${ }^{1}$ Department of Neurology, Division of Sleep Medicine, and Program in Neuroscience, Beth Israel Deaconess Medical Center and Harvard Medical School, \\ Boston, Massachusetts 02215, and 2Department of Pharmacology, University of Virginia, Charlottesville, Virginia 22908
}

Fever is a common phenomenon during infection or inflammatory conditions. This stereotypic rise in body temperature (Tb) in response to inflammatory stimuli is a result of autonomic responses triggered by prostaglandin E2 action on EP3 receptors expressed by neurons in the median preoptic nucleus ( $\mathrm{MnPO}{ }^{\mathrm{EP} 3 \mathrm{R}}$ neurons). To investigate the identity of $\mathrm{MnPO}^{\mathrm{EP} 3 \mathrm{R}}$ neurons, we first used in situ hybridization to show coexpression of EP3R and the VGluT2 transporter in MnPO neurons. Retrograde tracing showed extensive direct projections from $\mathrm{MnPO}^{\text {VGluT2 }}$ but few from $\mathrm{MnPO}^{\text {Vgat }}$ neurons to a key site for fever production, the raphe pallidus. Ablation of MnPO ${ }^{\text {VGluT2 }}$ but not $\mathrm{MnPO}^{\text {Vgat }}$ neurons abolished fever responses but not changes in Tb induced by behavioral stress or thermal challenges. Finally, we crossed EP3R conditional knock-out mice with either VGluT2-IRES-cre or Vgat-IRES-cre mice and used both male and female mice to confirm that the neurons that express EP3R and mediate fever are glutamatergic, not GABAergic. This finding will require rethinking current concepts concerning the central thermoregulatory pathways based on the MnP0 ${ }^{\mathrm{EP} 3 \mathrm{R}}$ neurons being GABAergic.

Key words: EPR3; fever; glutamatergic neurons; median preoptic nucleus; prostagladin receptor; raphe pallidus

\section{Significance Statement}

Body temperature is regulated by the CNS. The rise of the body temperature, or fever, is an important brain-orchestrated mechanism for fighting against infectious or inflammatory disease, and is tightly regulated by the neurons located in the median preoptic nucleus (MnP0). Here we demonstrate that excitatory MnPO neurons mediate fever and examine a potential central circuit underlying the development of fever responses.

\section{Introduction}

Fever is a critical sign of infectious and inflammatory diseases, an evolutionarily conserved response that may provide an advantage in fighting against replication of microorganisms (Blomqvist and Engblom, 2018; Garami et al., 2018). During an immune challenge, a brain-orchestrated series of autonomic responses produces the stereotypic rise of the body temperature $(\mathrm{Tb})$, which is triggered by prostaglandin E2 (PGE2) action on specific median preoptic (MnPO) neurons (Saper and Breder, 1994; Lazarus et al., 2007).

Intravenous administration of an inflammatory signal such as lipopolysaccharide (LPS) leads to a production of PGH2 by cy-

Received Nov. 26, 2019; revised Jan. 23, 2020; accepted Jan. 25, 2020.

Author contributions: N.L.S.M., S.B.G.A., and C.B.S. designed research; N.L.S.M. and S.S.B. performed research; N.L.S.M. and C.B.S. analyzed data; N.L.S.M. and C.B.S. wrote the paper.

This research was supported by U.S. National Institutes of Health Grants NS-085477, NS-072337, and HL-095491. We thank Dr. William Todd, Dr. Patrick Fuller, and Dr. Vetrivelan Ramalingam for advice as well as for sharing their viral vectors and other resources. We also thank Quan Ha, Minh Ha, Jumana Akoad, and Andrew Warfield for excellent technical assistance.

The authors declare no competing financial interests.

Correspondence should be addressed to Clifford B. Saper at csaper@bidmc.harvard.edu.

https://doi.org/10.1523/JNEUROSCI.2887-19.2020

Copyright $\odot 2020$ the authors clooxygenase 2 in endothelial cells and microglia along brain blood vessels (Engström et al., 2012; Eskilsson et al., 2017), and this is converted to PGE2 by PGE2-synthase in endothelial cells (García-Bueno et al., 2009). Blockade of cyclooxygenase in the region of the anterior tip of the third ventricle prevents the fever response (Scammell et al., 1998), suggesting that the PGE2 that causes fever is synthesized locally. There are four different PGE2 receptors in the hypothalamus, but only deletion of the EP3 receptor, either in the whole body or in the brain (Ushikubi et al., 1998; Oka et al., 2003) or in the MnPO (Lazarus et al., 2007) prevents fever responses to intraventricular PGE2 or to intravenous LPS.

The EP3R is densely expressed in the MnPO, the most responsive site for producing fever induced by injection of PGE2 in the brain (Scammell et al., 1996; Nakamura et al., 1999; Oka et al., 2000; Yoshida et al., 2003) and thought to be an inhibitory receptor (Vasilache et al., 2007). It was expected that fever was due to PGE2 inhibiting $\mathrm{MnPO}^{\mathrm{EP} 3 \mathrm{R}}$ inhibitory neurons, and immunohistochemical studies showed that these neurons expressed glutamic acid decarboxylase 67 (GAD1; Nakamura et al., 2002). In addition, $\mathrm{MnPO}{ }^{\mathrm{EP} 3 \mathrm{R}}$ neurons were shown to project to the dorsomedial hypothalamic nucleus (DMH)/dorsal hypothalamic 
area (DHA) and the raphe pallidus (RPa; Nakamura et al., 2009; Yoshida et al., 2009), two regions critically involved with thermoregulatory control (e.g., through thermogenesis and tail artery vasoconstriction; Nakamura et al., 2004, 2009; Yoshida et al., 2009; Tanaka et al., 2011, 2013; Machado et al., 2018). Together, this evidence gave rise to a model of GABAergic $\mathrm{MnPO}^{\mathrm{EP} 3 \mathrm{R}}$ neurons tonically inhibiting thermogenesis from the $\mathrm{RPa}$ or the DMH/DHA, and that PGE2 inhibited this pathway, thus releasing a fever response (Morrison and Nakamura, 2019).

The role of GABAergic neurons in thermoregulatory control has recently been questioned by the observation that activation of preoptic area (POA) neurons that express the vesicular GABA transporter (Vgat; essential for the synaptic release of GABA and glycine) produced little or no effect on Tb (Song et al., 2016; Yu et al., 2016). Conversely, selective stimulation of MnPO neurons that express the vesicular glutamate 2 transporter (VGluT2; hence, $\mathrm{MnPO}^{\text {VGluT2 }}$ neurons) produces a profound reduction of Tb (Song et al., 2016; Yu et al., 2016; Abbott and Saper, 2017). Moreover, many of the neurons in the POA that express GAD1 or GAD2 do not express Vgat, but instead produce VGluT2 (Moffitt et al., 2018). $\mathrm{GAD}^{+}$but $\mathrm{Vgat}^{-}$cell groups include those expressing the peptides PACAP and galanin, which cause hypothermia when stimulated (Tan et al., 2016; Kroeger et al., 2018). These results suggest that some of the GAD1 ${ }^{+}$and $\mathrm{GAD}_{2}{ }^{+}$neurons in the POA may use glutamate, not GABA, as their neurotransmitter to control body temperature. However, it is not known whether the $\mathrm{MnPO}^{\mathrm{EP} 3 \mathrm{R}}$ neurons that cause fever are glutamatergic.

To investigate this possibility, we first used in situ hybridization to reveal whether $\mathrm{MnPO}^{\mathrm{EP} 3 \mathrm{R}}$ neurons express VGluT2. We then used a retrograde tracer method in transgenic reporter mice expressing GFP in either Vgat or VGluT2 neurons to show the identity of RPa-projecting MnPO neurons, then genetically directed ablation of $\mathrm{MnPO}^{\text {Vgat }}$ and $\mathrm{MnPO}^{\text {VGluT2 }}$ neurons to determine the role of these neurons in regulating fever induced by LPS, behavioral stress, or thermal challenges. Finally, we crossed EP3R conditional knock-out mice (EP3R ${ }^{\text {flox }}$ mice; Lazarus et al., 2007) with either VGluT2-IRES-cre or Vgat-IRES-cre mice to cause deletion of EP3R from excitatory $\left(\mathrm{VGluT2}^{+}\right)$or inhibitory $\left(\mathrm{Vgat}^{+}\right)$neurons, respectively, and tested these animals for their ability to produce a fever response.

\section{Materials and Methods}

Animals. All animal care and experimental procedures were approved by the Beth Israel Deaconess Medical Center Institutional Animal Care and Use Committee. We used male mice for functional experiments and male or female mice were used for anatomical investigations. Prostaglandin E receptor 3 (subtype EP3R) flox mice

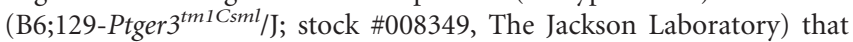
has loxP sites flanking exon 1 of the Ptger 3 gene (EP3R ${ }^{\text {flox }}$; Lazarus et al., 2007), VGluT2-crexEP3R ${ }^{\text {flox }}$, and Vgat-crexEP3R ${ }^{\text {flox }}$ mice. VGluT2crexPtger3 floxed mice were generated by crossing Ptger 3 homozygous

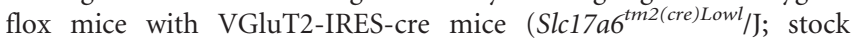
\#016963, The Jackson Laboratory), and the resultant offspring that were heterozygous for Ptger3Rflox and VGluT2-cre were again crossed with ptger3R homozygous flox mice to get VGluT2-creXEP3R ${ }^{\text {flox }}$ mice, in which exon 1 of ptger3 gene is deleted in the VGluT2-cre neurons. Likewise, VgatcrexPtger3 floxed mice were generated by crossing Ptger3Rflox

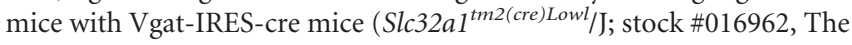
Jackson Laboratory), and the resultant offspring that are heterozygous for Ptger flox and Vgat-cre were again crossed with ptger3 homozygous flox mice to get Vgat-crexEP3R ${ }^{\text {flox }}$ mice. In these mice, ptger 3 gene is deleted in the Vgat neurons. We used also Vgat-IRES-Cre male mice, some of which were mated to Cre-dependent GFP reporter mice (VgatIRES-Cre;R26-loxSTOPlox-L10-GFP), VGluT2-IRES-Cre, VGluT2-
IRES-Cre-GFP (VGluT2-IRES-Cre;R26-loxSTOPlox-L10-GFP), PACAPIRES-cre (Todd et al., 2018), and PACAP-IRES-cre-GFP (PACAP-IRESCre;R26-loxSTOPlox-L10-GFP) mice.

The age of mice at the time of experimentation ranged between 12 and 30 weeks. Mice were individually housed in standard plastic cages with standard corn cob bedding with nesting materials on a $12 \mathrm{~h}$ light/dark cycle at ambient temperatures ranging between $20^{\circ} \mathrm{C}$ and $24^{\circ} \mathrm{C}$. All recordings were performed in the home cages at this temperature, unless mice were exposed to thermal challenge $\left(4^{\circ} \mathrm{C}\right.$ or $\left.37^{\circ} \mathrm{C}\right)$, in which case the cage was moved for that experiment to an environmental chamber. Mouse chow (F6 Rodent Diet 8664, Teklad) and water were provided ad libitum.

Surgery. All surgeries were performed in sterile conditions. Mice were anesthetized with ketamine/xylazine (100 and $10 \mathrm{mg} / \mathrm{kg}$, i.p., respectively) with additional doses of $10 \%$ of the initial dose throughout surgery as needed to eliminate the withdrawal reflex. Stereotaxic microinjections were made into the $\mathrm{MnPO}$ [coordinates from bregma: anteroposterior $(\mathrm{AP})=+0.43 \mathrm{~mm}$, lateral $(\mathrm{L})=0.0$, dorsoventral $(\mathrm{DV})=$ $-4.6 \mathrm{~mm}$ ) and $\mathrm{RPa}$ (coordinates from Lambda: $\mathrm{AP}=-2.2 \mathrm{~mm}, \mathrm{~L}=0.0$, $\mathrm{DV}=-5.5 \mathrm{~mm})$.

Mice were implanted with a radiotelemetry temperature sensor (TA-F10, DSI) in the intraperitoneal space via laparotomy. Meloxicam treatment, for analgesia, was administered before surgery. Mice were allowed to recover at least $10 \mathrm{~d}$ before experimentation. Following recovery, mice showed no signs of discomfort and gained weight normally.

Neural tracers and viral vectors. AAV-iCre-2A-Venus (serotype 8; titer $=9.4 \times 10^{12}$ genome copies $/ \mathrm{ml}$ ) was donated by Dr. Rolf Sprengel from the University of Heidelberg, Heidelberg, Germany (Tang et al., 2009). This plasmid was then cloned and sequenced in our laboratory by Dr. Patrick Fuller and packaged by the Harvard Gene Therapy Initiative, Boston, MA, by Dr. Jeng-Shin Lee in adeno-associated virus (AAV) and AAV-GFP was used as a control (Todd et al., 2018). AAV conditionally expressing subunit A of diphtheria toxin in a Cre-dependent manner (AAV-lox-mCherry-lox-DTA-lox2; or AAV-Flex-DTA) was prepared by Dr. Patrick fuller and packaged by Dr. Caroline Bass at SUNY University, Buffalo, NY (Kaur et al., 2017). Cholera toxin subunit B (CTb; $1-2 \%$ diluted in saline; catalog \#103A, List Biological Laboratories) was microinjected for retrograde anatomical experiments in a volume of 6-9 nl.

Intraperitoneal injection. LPS from Escherichia coli 0111:B4 (catalog \#L2630, Sigma-Aldrich) was used at doses of $0.01,0.02,0.1$, or $1.0 \mathrm{mg} / \mathrm{kg}$, and compared with saline. When multiple LPS injections were performed, we used a random order at 1 week intervals, between 11:00 A.M. and 12:00 P.M. EST (Eastern Standard Time).

Body temperature and locomotor activity recordings. Tb and locomotor activity (LMA) were recorded using the radiotelemetry DSI system. The signal was sent from the telemetry probes previously implanted to receivers and converted using the PhysioTel HD and PhysioTel (DSI) hardware, which provides the mean of $\mathrm{T}_{\mathrm{b}}$ every $5 \mathrm{~min}$.

Stress protocol. Singly housed mice were switched to an empty cage that was previously occupied by a single male (cage exchange stress). Stress protocols were performed between 11:00 A.M. and 12:00 P.M. EST, and food and water were provided during the protocols ad libitum (Machado et al., 2018).

Thermal challenge protocol. Singly housed mice were habituated for $3 \mathrm{~d}$ in an environmental chamber at $22^{\circ} \mathrm{C}$, then mice were exposed to thermal challenges $\left(4^{\circ} \mathrm{C}\right.$, cold; or $37^{\circ} \mathrm{C}$, warm $)$ for $4 \mathrm{~h}$ starting between 11:00 A.M. and 12:00 P.M. EST. Food and water were provided during the protocols ad libitum.

Perfusion and brain sectioning. After performing the experimental protocols or 7-10 d after CTb injections mice were deeply anesthetized with chloral hydrate ( $1.5 \%$ body weight, i.p., $7 \%$ solution) and transcardially perfused with $30 \mathrm{ml}$ of PBS and then $30 \mathrm{ml}$ of $10 \% \mathrm{pH}$ neutral formalin (Thermo Fisher Scientific). Brains were extracted and postfixed overnight in $10 \%$ formalin and then stored in $20 \%$ sucrose until sectioned using a freezing microtome ( $40 \mu \mathrm{m}$ coronal sections into three series). Following sectioning, tissue was stored at $4^{\circ} \mathrm{C}$ in PBS containing the preservative sodium azide until processed for histology.

Injection sites. To confirm the injection sites, one series of the tissue was mounted and coverslipped with hard-set mounting media (Vectashield) for 
native fluorescence (GFP or mCherry). We used a mouse brain atlas (Franklin and Paxinos, 2008) to determine coordinates for injection sites. Only animals with the histological confirmation of the region targeted were used for analyses. We used a heatmap showing overlapping of the AAV-mCherry-DTA ${ }^{+}$injection sites of every mouse used in these experiments. To construct the heatmap, we converted the photomicrography of the injection site into a binary one, applied a Gaussian filter to remove remaining noise, and stacked them together using Matlab (Machado et al., 2018).

In situ hybridization. One or two series of the POA brain sections from EP3R ${ }^{\text {flox }}$, VGluT2-crexEP3R $R^{\text {flox }}$, Vgat-crexEP3R $R^{\text {flox }}$, and PACAP-IREScre male or female mice were used for Ptger3 (EP3R) mRNA, Slc17a6 (VGluT2), or Slc32al (Vgat) mRNA labeling by RNA scope in situ hybridization. For this, brains were sectioned at $30 \mu \mathrm{m}$ and then mounted on Superfrost Plus slides in RNAase-free conditions. The slides were then warmed in a dry oven for $30 \mathrm{~min}$ at $40^{\circ} \mathrm{C}$, and an RNAScope Multiplex Fluorescent Reagent Kit V2 (catalog \#323100, Advanced Cell Diagnostics) was applied over the tissue area. All sections were pretreated with hydrogen peroxide for $20 \mathrm{~min}$ at room temperature, and target retrieval was performed for $5 \mathrm{~min}$ by placing the slides in a steamer $\left(>99^{\circ} \mathrm{C}\right)$. Then the sections were dehydrated in $90 \%$ alcohol and air dried for $5 \mathrm{~min}$, followed by a treatment with protease reagent (Protease III) for 30 min at $40^{\circ} \mathrm{C}$. After rinsing in sterile water, sections were incubated in their respective RNA-scope probes for Ptger3-C1 (RNAscope ProbeMm-Ptger3; catalog \#504481, Advanced Cell Diagnostics), Slc17a6C1(RNAscope Probe- Mm-Slc17a6; catalog \#319171, Advanced Cell Diagnostics), and Slc32al-C1(RNAscope Probe- Mm-Slc32al; catalog \#319191, Advanced Cell Diagnostics) for $2 \mathrm{~h}$ at $40^{\circ} \mathrm{C}$ for hybridization. Sections were then incubated in three amplification reagents at $40^{\circ} \mathrm{C}$ (AMP1, AMP2 for $30 \mathrm{~min}$ each, and AMP3 for $15 \mathrm{~min}$ ) and followed by horseradish peroxidase-C1 (HRP-C1) amplification at $40^{\circ} \mathrm{C}$ for $15 \mathrm{~min}$. Sections were incubated in TSA (Trichostatin A) plus Fluorescein or Cy5 fluorophores (catalog \#NEL741001, PerkinElmer) in a 1:750 concentration for 30 min to visualize (channel 1 at $488 \mathrm{~nm}$ ) Ptger3 and VGluT2/ Vgat $($ at $688 \mathrm{~nm}$ ) mRNA. In the last step of the process, sections were subjected to HRP blocking for $15 \mathrm{~min}$ at $40^{\circ} \mathrm{C}$. After each of the protocol steps, sections were washed with $1 \times$ in the wash buffer provided in the kit. Slides were dried and coverslipped with Vectashield antifade mounting medium (catalog \#H-1400, Vector Laboratories).

Immunohistochemistry. All sections were processed free floating and conducted at room temperature. For CTb immunofluorescence, the sections of the tissue were rinsed and incubated in a blocking solution of $10 \%$ horse serum, then rinsed and incubated with primary antibody overnight (Goat anti-CTb; catalog\#703, List Biological Laboratories). The CTb antibody did not stain anything in sections from brains that had not been injected. For streptavidin immunochemistry, we used the following secondary antibodies: donkey anti-goat biotinylated-IgG (1:1000; Jackson ImmunoResearch); followed by Invitrogen Cy5-conjugate streptavidin (1:500; catalog \#SA1011, Thermo Fisher Scientific) or Cy3conjugate streptavidin (1:500; catalog \#016-160-084, Jackson ImmunoResearch) to visualize fluorescence. Sections were then rinsed and mounted onto glass slides, slides were dried, and coverslipped with Vectashield.

Following the VGluT2, Vgat or EP3R RNAscope in situ hybridization, immunolabeling of GFP was performed on the same sections. Sections were incubated in Rabbit anti-GFP (1:7500; Catalog\#A6455; Lot\#1220284; Molecular probes) overnight at $4^{\circ} \mathrm{C}$, washed in PBS $(2 \times 2$ $\mathrm{min}$ ) and incubated in secondary antibody (Alexa Fluor 488 donkey anti-Rabbit; 1:500; catalog \#A-21206, Life Technologies) for $2 \mathrm{~h}$ at room temperature. After another round of washes, slides were dried and coverslipped with Vectashield.

Quantitative analyses of histology. For all experiments counting number of colocalizations in the $\mathrm{MnPO}$, we counted neuronal profiles with clearly defined nuclei located at two or three levels of coronal sections (30 or $40 \mu \mathrm{m}$ ) from the MnPO. The most rostral coronal section was taken from the beginning of the third ventricle over and around the dorsal cap of the organum vasculosum of the lamina terminalis (OVLT; bregma $+0.5 \mathrm{~mm}$; Franklin and Paxinos, 2008). For the second and third coronal sections, we counted neuronal profiles ventral to and around the middle of the anterior commissure (ac); the ventral part extended to the upper border of the third ventricle (bregma +0.14 to +0.38 ).

To determine the number of colocalizations in the ventrolateral preoptic nucleus (VLPO; bregma -0.10 to +0.14 ), we counted neuronal profiles from two coronal sections $(40 \mu \mathrm{m})$ at the level and caudal to the end of the ac; both sections were rostral to the most rostral part of the paraventricular nucleus of the hypothalamus. An Abercrombie correction was applied to all cell counts (Guillery, 2002).

Statistical analysis. Statistical analyses were performed using GraphPad Prism version 7 (GraphPad Software). Following a test for normality (D’Agostino and Pearson omnibus test), significant differences were determined using either repeated-measures one-way ANOVA or two-way ANOVA both followed by Bonferroni's correction or, for statistical tests between two groups, an unpaired $t$ test or paired $t$ test was used. Data are presented as the mean \pm SEM. The statistical test used, statistical significance, and number of animal subjects per group are reported in the Results or figure legends; data were considered to be statistically significant when $p<0.05$. We used power analyses (www.biomath.info) using means and SDs derived from our data, which show that our study was powered to detect a $0.67^{\circ} \mathrm{C}$ change in $\mathrm{Tb}$ with $>80 \%$ reliability for $\mathrm{EP} 3 \mathrm{R}^{\text {flox }}$ mice. For the VGluT2-crexEP3R ${ }^{\text {flox }}$ mice, our study was powered to detect an effect size of a $0.87^{\circ} \mathrm{C}$ change in $\mathrm{Tb}$ with $>80 \%$ reliability, and for Vgat-crexEP3R flox mice the effect size of a $0.62^{\circ} \mathrm{C}$ change in Tb with $>80 \%$ reliability.

\section{Results \\ MnPO $^{\text {VGluT2 }}$ and VLPO ${ }^{\text {VGluT2 }}$ neurons express EP3R and innervate the $\mathrm{RPa}$}

First, we used the RNA-scope in situ hybridization technique to label Ptger3 (EP3R) exon 1 mRNA (Fig. 1a, red) and Slc17a6 (VGluT2; Fig. 1b,c, green) to determine whether glutamatergic MnPO neurons coexpress EP3R (Fig. 1c). We found that virtually all MnPO neurons expressing EP3R mRNA also contained VGluT2 mRNA [96.48 $\pm 0.18 \%$ (mean \pm SEM) of the EP3Rexpressing MnPO neurons were VGluT2 ${ }^{+}$cells, $N=2$ ]. To identify the phenotype of $\mathrm{MnPO}$ neurons projecting to $\mathrm{RPa}$, we used a retrograde traditional tracer method $(\mathrm{CTb})$ injected into the $\mathrm{RPa}$ of three VGluT2-IRES-cre $\times$ L10-GFP reporter mice (Fig. $1 d)$ and two Vgat-IRES-cre $\times$ L10-GFP reporter mice (Fig. $1 k$ ). Using this methodology, we found that $92 \pm 3.0 \%$ (mean \pm $\mathrm{SEM}$ ) of the RPa-projecting (magenta) MnPO neurons were glutamatergic (Fig. 1e,f,i,j, green), while $\mathrm{MnPO}^{\text {Vgat }}$ neurons (Fig. $1 g-j$, green) accounted for only $6.63 \pm 1.63 \%$ of RPa-projecting (red) neurons. This result confirms our previous anterograde tracing observations of abundant RPa-projecting MnPO VGluT2 innervation, but sparse $\mathrm{MnPO}^{\text {Vgat }}$ projections to the $\mathrm{RPa}$ (Abbott et al., 2016). Surprisingly, we also revealed a similar percentage of $\mathrm{RPa}$-projecting glutamatergic and GABAergic neurons in the VLPO $[91.9 \pm 2.0 \%$ of neurons labeled with CTb also expressed VGluT2 $^{+}$(Fig. 1t-v), while $12.5 \pm 12 \%$ of CTb-labeled neurons expressed $\mathrm{Vgat}^{+}$(Fig. 1p)]. Together, these anatomical observations suggest that EP3R-expressing POA VGluT2 neurons may project to and modulate the activity of the RPa neurons directly. However, $\mathrm{MnPO}^{\text {Vgat }}$ and VLPO Vgat neurons have little direct input to the RPa (Fig. 1p,q). Thus, RPa-projecting MnPO VGluT2 and VLPO ${ }^{\text {VGluT2 }}$ neurons may represent at least a subpopulation of the neurons shown to produce a fall in $\mathrm{Tb}$ after chemogenetic activation or optogenetic stimulation of preoptic glutamatergic neurons (Abbott and Saper, 2017; Zhao et al., 2017). In addition, the VLPO ${ }^{\text {Galanin }}$ neurons shown by Kroeger et al. (2018) to cause hypothermia when activated chemogenetically are probably glutamatergic neurons and are likely to be distinct from the VLPO $^{\text {Galanin }}$ GABAergic neurons that regulate sleep. 

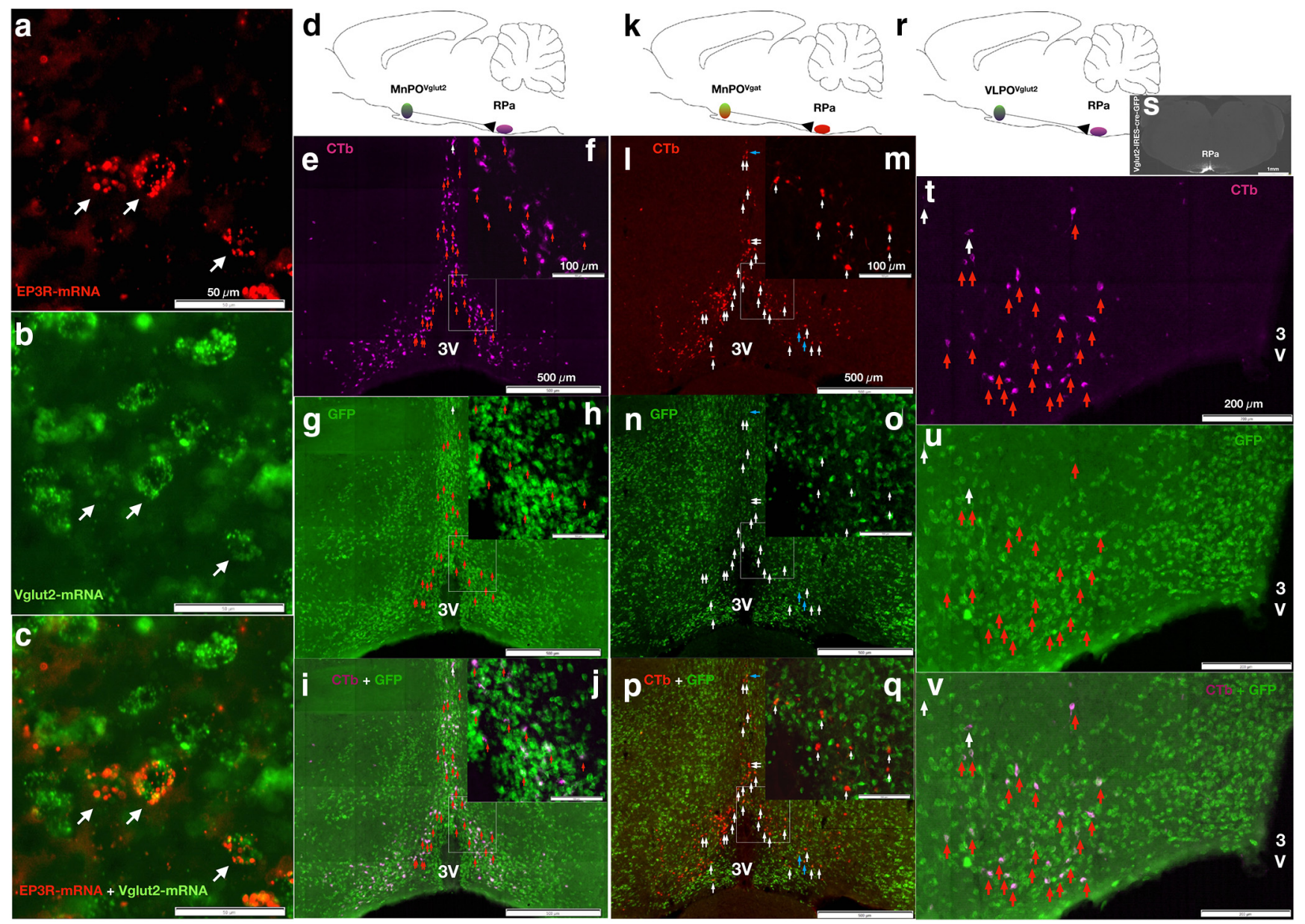

Figure 1. Glutamatergic neurons in the MnP0 and VLP0 express EP3R and innervate the RPa. $\boldsymbol{a}$, RNA-scope in situ hybridization reveal EP3R-expressing neurons (red) in the MnP0 of an EP3R flox mouse $\left[96.48 \pm 0.18 \%\right.$ (mean \pm SEM) of the EP3R-expressing MnPO neurons were VGluT2 ${ }^{+}$cells, $\left.n=2\right]$. $\boldsymbol{b}$, RNA-scope in situ hybridization for VGluT2 (in green). $\boldsymbol{c}$, White arrows demonstrate neurons coexpressing EP3R (red) and VGluT2 (green). $\boldsymbol{d}$, Schematic figure of retrograde traditional tracer (CTb) injected in the RPa of VGluT2-IRES-cre-GFP mouse. e-j, RPa-projecting MnPO neurons (magenta) with higher mag view (e) of box in $\boldsymbol{f}, \mathrm{MnPO} \mathrm{V}^{\mathrm{Vglut} 2}$ neurons (green) with higher mag view $(\boldsymbol{g})$ in $\boldsymbol{h}$, and the merged image with of RPa-projecting MnPO $\mathrm{V}^{\mathrm{V} \text { lut } 2}$ neurons $(\boldsymbol{i})$ showing overlap (white; $92 \pm 3.0 \%$ of all retrogradely labeled neurons), red arrows demonstrating (Tb labeled/VGluT2 ${ }^{+}$cells, and a white arrow showing a single CTb labeled non-VGluT2 cells, with j showing a higher mag view. $\boldsymbol{k}$, Schematic figure of retrograde traditional tracer (CTb) injected in the RPa of Vgat-IRES-cre-GFP. $\boldsymbol{I} \boldsymbol{q} \boldsymbol{q}$, RPa-projecting MnP0 neurons (red) with higher mag view ( $\boldsymbol{m})$; MnPO Vgat neurons (green) with higher mag view $(\boldsymbol{n}, \boldsymbol{o})$; and the merged image $(\boldsymbol{p})$ with doubly labeled neurons in yellow $(6.63 \pm 1.63 \%)$, blue arrows marking the few $\left(\mathrm{Tb}\right.$ labeled/Vgat ${ }^{+}$cells, and white arrows (Tb mark retrogradely labeled non-Vgat cells, with higher mag view $(\boldsymbol{q})$. $\boldsymbol{r}$, Schematic figure of retrograde traditional tracer (CTb) injected in the RPa of VGluT2-IRES-cre-GFP mouse. $\boldsymbol{s}$, Representative fluorescence image of the (Tb injection in the RPa. $\boldsymbol{t}-\boldsymbol{v}$, RPa-projecting VLPO neurons (magenta; $\boldsymbol{t}$ ), VLPO ${ }^{\mathrm{Vglut} 2}$ neurons (green; $\boldsymbol{u}$ ), and the merged image (white) of RPa-projecting (magenta) VLPO Vglut2 2 neurons (green) in the bottom panel ( $\boldsymbol{v} ; \sim 91.9 \pm 2.0 \%$ of the CTb-labeled neurons show colocalization with VGluT2), red arrows demonstrate colocalization of CTb labeled in theVGluT2 ${ }^{+}$cells, and white arrows CTb-labeled non-VGluT2 cells. 3V, Third ventricle.

\section{$\mathrm{PACAP}^{+}$neurons in the preoptic area coexpress EP3R and project to the $\mathrm{RPa}$}

Tan et al. (2016) reported that $\mathrm{MnPO}^{\mathrm{PACAP} / \mathrm{BDNF}+}$ cells are warm-responsive neurons and when activated optogenetically produced a reduction in $\mathrm{Tb}$ (Tan et al., 2016). We therefore used in situ hybridization for Ptger3 (EP3R) exon $1 \mathrm{mRNA}$ labeling or VGluT2 mRNA in tissue from MnPO of two PACAP-IRES-CreGFP reporter mice to determine whether the $\mathrm{MnPO}^{\mathrm{EP} 3 \mathrm{R}}$ neurons are related to this PACAP population. We found that a majority of $\mathrm{MnPO}^{\mathrm{EP} 3 \mathrm{R}}$ (Fig. 2a, red) neurons express PACAP [Fig. $2 b, c$, green; $77.06 \pm 0.13 \%$ (mean \pm SEM) of the EP3R-expressing $\mathrm{MnPO}$ neurons were $\mathrm{PACAP}^{+}$cells, $N=2$ ]. Using $\mathrm{CTb}$ as a retrograde tracer in the RPa (Fig. $2 e$, red) of PACAP-IRES-creGFP mice, we also found that $76 \pm 3.6 \%$ of the RPa-projecting $\mathrm{MnPO}$ neurons are $\mathrm{PACAP}^{+}$cells (Fig. $2 f-h$, green). In addition, a majority of $\mathrm{MnPO}^{\mathrm{PACAP}}$ neurons were found to be glutamatergic (Fig. $2 i, k$, magenta; $55.66 \pm 8.67 \%$ of the $\mathrm{MnPO}^{\text {PACAP }}$ neurons show colocalization with VGluT2 mRNA, $N=3$ ), whereas only $2.21 \pm 0.27 \%$ of PACAP cells in the MnPO show colocalization with mRNA for Vgat $(N=3$; Fig. $2 l-n)$. Similarly, Zhao et al. (2017) demonstrated that $\mathrm{BDNF}^{+}$neurons in the $\mathrm{MnPO}$ are mainly glutamatergic $(59.8 \%$ of BDNF cells in the $\mathrm{MnPO}$ were VGluT2 $^{+} ; 32.9 \%$ of BDNF cells in the MnPO were Vgat $\left.{ }^{+}\right)$. Finally, $40.5 \pm 7.8 \%(N=3)$ of the RPa-projecting VLPO neurons (red) were $\mathrm{PACAP}^{+}$neurons (Fig. $2 p-r$ ). Thus, although Tan et al. (2016) had concluded that most of the PACAP/BDNF warmsensitive cells in the MnPO contained GAD2, and were therefore GABAergic, it appears that most of these cells are instead glutamatergic.

\section{Ablation of $\mathrm{MnPO}^{\mathrm{VGluT2}}$ neurons precludes fever responses}

We then used cell-specific ablation (using a Cre-dependent AAV-DTA that produces diphtheria toxin A in Cre-expressing neurons) in the MnPO of VGluT2-IRES-cre mice or VGluT2IRES-cre-GFP reporter mice (VGluT2-cre-DTA mice; DTA_VGluT2), and WT littermates (WT-DTA; DTA_WT) as controls 

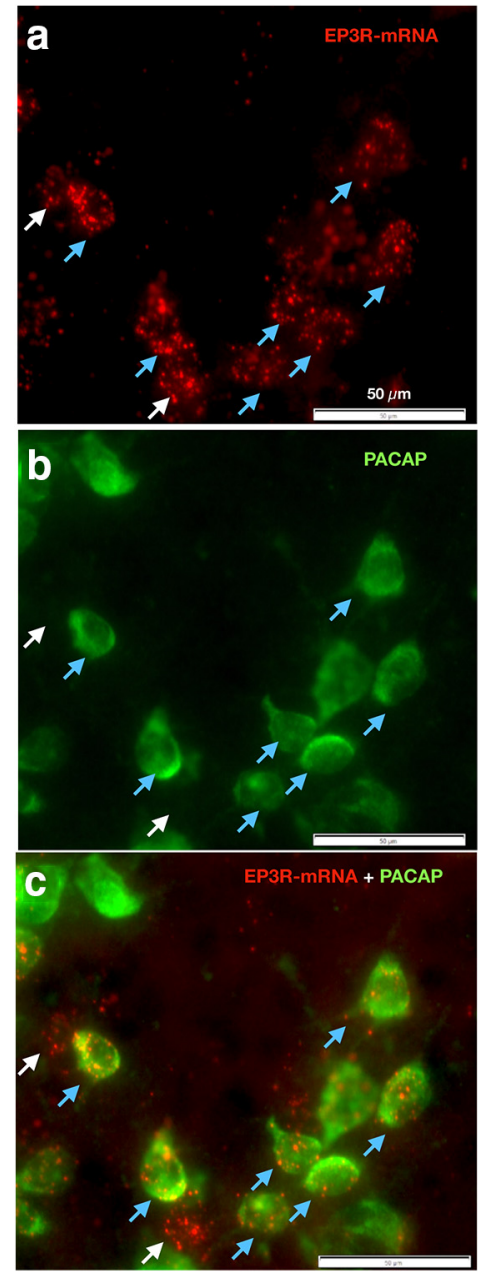

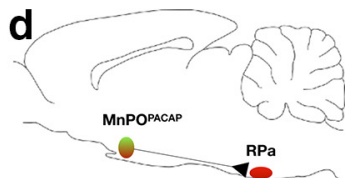

h
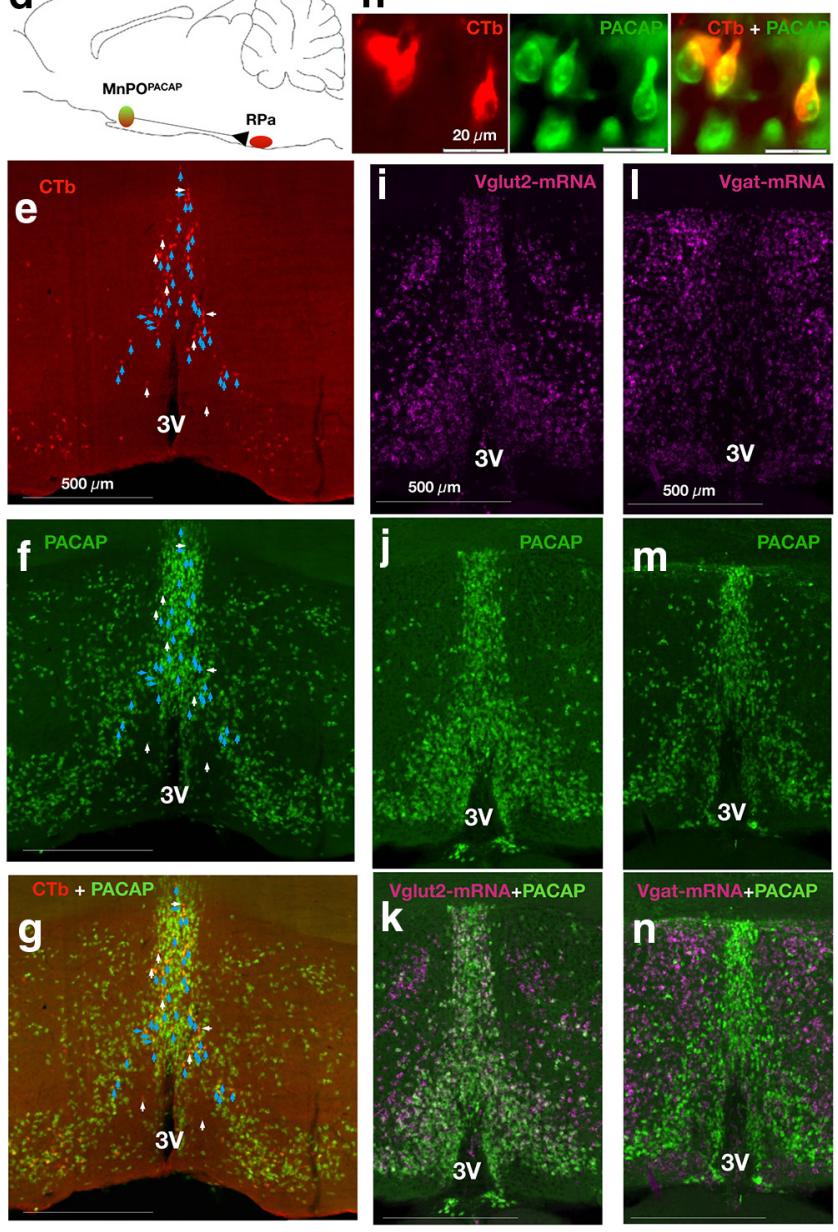
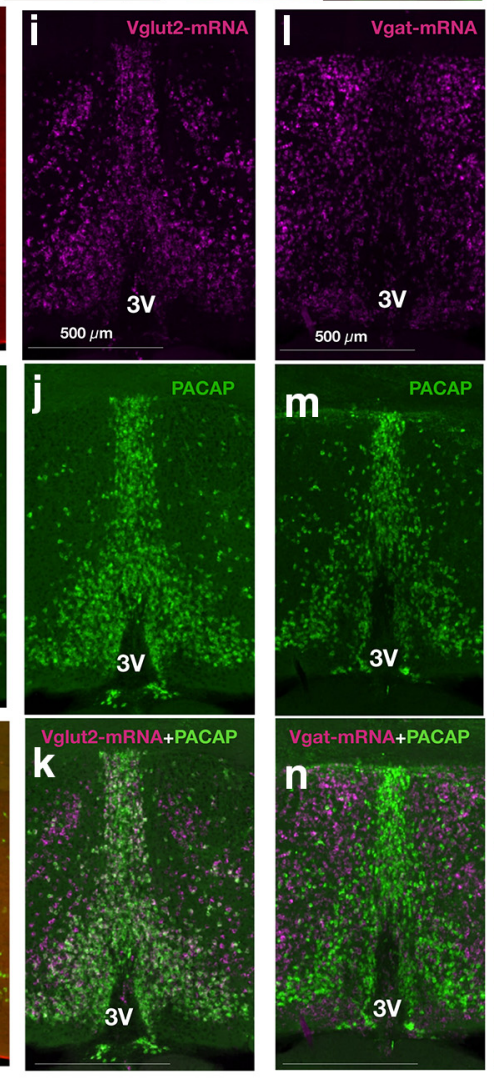

0
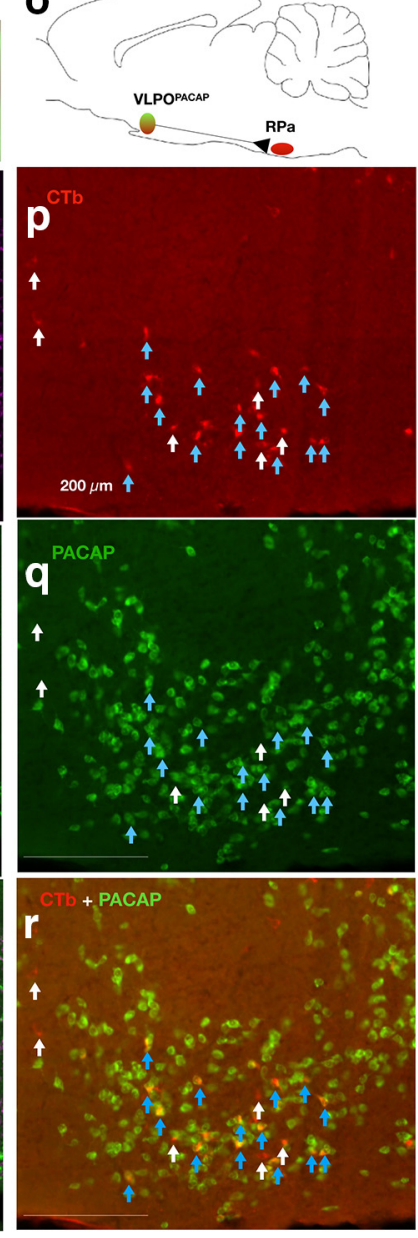

Figure 2. PACAP ${ }^{+}$neurons in the MnP0 and VLP0 express EP3R and innervate the RPa. $\boldsymbol{a}$, RNA-scope in situ hybridization reveals EP3R-expressing neurons (red) in the MnP0 of a PACAP-IRESCre-GFP mouse. $\boldsymbol{b}, \mathrm{PACAP}^{+}$neurons (green) in the MnPO. $\boldsymbol{c}$, Blue arrows demonstrate neurons coexpressing EP3R (red) and PACAP ${ }^{+}$neurons (green), and white arrows show EP3R-expressing MnPO non-PACAP cells [77.06 $\pm 0.13 \%$ (mean \pm SEM) of the EP3R-expressing MnPO neurons were PACAP ${ }^{+}$cells]. $\boldsymbol{d}$, Schematic figure of retrograde traditional tracer (CTb) injected in the RPa of PACAP-IRES-cre-GFP mouse. $\boldsymbol{e}-\boldsymbol{g}$, RPa-projecting MnPO neurons (red; $\boldsymbol{e}$ ), MnPOPACAP neurons (green; $\boldsymbol{f}$ ), and the merged image with yellow doubly labeled neurons $(\sim 76 \pm 3.6 \%$ ), blue arrows demonstrate colocalization of (Tb and PACAP, and white arrows CTb labeled non-PACAP cells $(\boldsymbol{g}) \cdot \boldsymbol{h}$, Higher magnification image of the RPa-projecting (red) MnP0 ${ }^{\text {PACAP }}$ neurons ( green) from $\boldsymbol{g}$. $\boldsymbol{i}-\boldsymbol{k}$, RNA-scope in situ hybridization for VGluT2 mRNA (magenta) in tissue from PACAP-IRES-Cre-GFP reporter mouse (i), PACAP cells in the MnP0 (green; $j$ ), and $\boldsymbol{k}$ shows the colocalization (white) of PACAP and VGluT2 (55.66 $\pm 8.67 .4 \%$ of the MnP0 PACAP neurons show colocalization with VGluT2 $\left.{ }^{+} ; n=3\right)$. $I-n$, RNA-scope in situ hybridization for Vgat mRNA (magenta) in tissue from aPACAP-IRES-Cre-GFP reporter mouse $(I)$, PACAP cells in the MnPO ( $g r e e n ; \boldsymbol{m}$ ), and PACAP neurons and Vgat (only $2.21 \pm 0.27 \%$ of PACAP cells in the MnPO show colocalization with mRNA for Vgat; $\boldsymbol{n}) . \boldsymbol{o}$, Schematic figure of retrograde traditional tracer (CTb) injected in the RPa of PACAP-IRES-cre-GFP mouse. $\boldsymbol{p}-\boldsymbol{r}$, RPa-projecting VLPO neurons (red; $\boldsymbol{p}$ ), VLP0 ${ }^{\text {PACAP }}$ neurons ( $g$ reen; $\boldsymbol{q}$ ), and the merged image (yellow) showing RPa-projecting (red) VLPO ${ }^{\text {PACAP }}$ neurons (green; $40.5 \pm 7.8 \%$ of the (Tb labeled neurons also expressed PACAP), blue arrows demonstrate colocalization of CTb and PACAP, and white arrows CTb labeled non-PACAP cells $(r)$. 3V, Third ventricle.

(Fig. $3 a$ ) to test whether MnPO ${ }^{\text {VGluT2 }}$ neurons are necessary for febrile responses.

Our results demonstrated that ablation of MnPO ${ }^{\text {VGluT2 }}$ neurons $(n=6$; Fig. $3 b, d)$ at $22^{\circ} \mathrm{C}$ ambient temperature produced no change in mean $24 \mathrm{~h}$ baseline $\mathrm{Tb}$ (DTA_VGluT2, 36.4 $\pm 0.03^{\circ} \mathrm{C}$; DTA_WT, $36.59 \pm 0.04^{\circ} \mathrm{C} ; p=0.78$, two-way ANOVA) or LMA (DTA_VGluT, $21.7 \pm 0.1 \mathrm{cpm}$; DTA_WT, $3.0 \pm 0.16 \mathrm{cpm} ; p=$ 0.80 , two-way ANOVA) compared with intact WT-DTA mice $(N=6)$ during $24 \mathrm{~h}$ of the baseline recording (Fig. $3 c$ ).

However, when VGluT2_DTA mice were treated with LPS $\left(0.2 \mathrm{mg} / \mathrm{kg}\right.$ ), we found virtually no fever response (peak, $\sim 0.4^{\circ} \mathrm{C}$ ) compared with the same mice treated with saline $(n=6)$. By contrast, WT-DTA mice treated with LPS $(n=6)$ showed a fever of $\sim 1.8^{\circ} \mathrm{C}$ compared with the same WT-DTA mice treated with saline. Analyses were made during the $2 \mathrm{~h}$ peak of fever after the initial hyperthermia induced by handling stress, $1-3 \mathrm{~h}$ after the LPS or saline injections (Fig. 3e; DTA_VGluT2 LPS, $36.64 \pm$ $0.02^{\circ} \mathrm{C}$; DTA_VGluT2 saline, $36.23 \pm 0.04^{\circ} \mathrm{C}$; WT_LPS $37.14 \pm$ $0.06^{\circ} \mathrm{C}$; DTA_WT saline, $35.91 \pm 0.04^{\circ} \mathrm{C} ;{ }^{* * *} p<0.001,{ }^{* * * *} p<$ $0.0001 ; F_{(3,355)}=102.2$, two-way ANOVA, followed by Bonferroni's post hoc test; $N=6$ DTA_VGluT2 LPS; $N=6$ DTA_ VGluT2 saline; $N=6$ DTA_WT LPS; $N=3$ DTA_WT saline). VGluT2-cre-DTA mice treated with LPS or saline showed no differences in their LMA patterns, and no changes in LMA were observed between the two groups treated with LPS (DTA VGluT2 LPS, $0.5 \pm 0.09 \mathrm{cpm}$; DTA_WT LPS, $0.35 \pm 0.07 \mathrm{cpm}$; DTA_VGluT2 saline, $0.99 \pm 0.19 \mathrm{cpm}$; DTA_WT SAL, $1.24 \pm$ $0.24 ; p=0.09, F_{(3,350)}=2.1$, two-way ANOVA, followed by Bonferroni's post hoc test; $N=6$ DTA_VGluT2 LPS; $n=6$ DTA_VGluT2 saline; $N=6$ DTA_WT LPS; $N=3$ DTA_WT saline; Fig. $3 e, g)$.

These same mice were also subjected to a cage exchange stress protocol (being placed in a cage previously occupied by another male mouse) to test whether MnPO ${ }^{\text {VGluT2 }}$ neurons modulate 
a

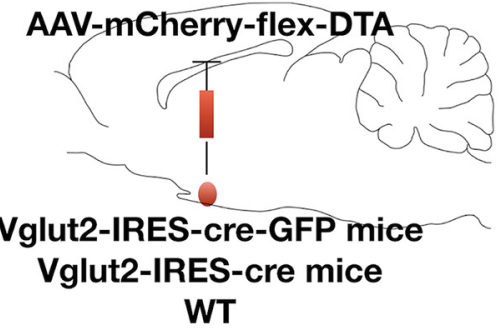

b

\section{Rostral}

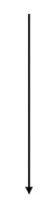

Caudal

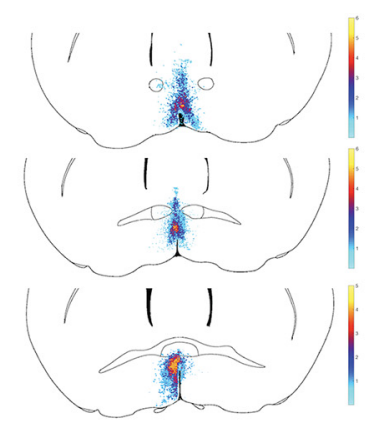

C

\section{d}
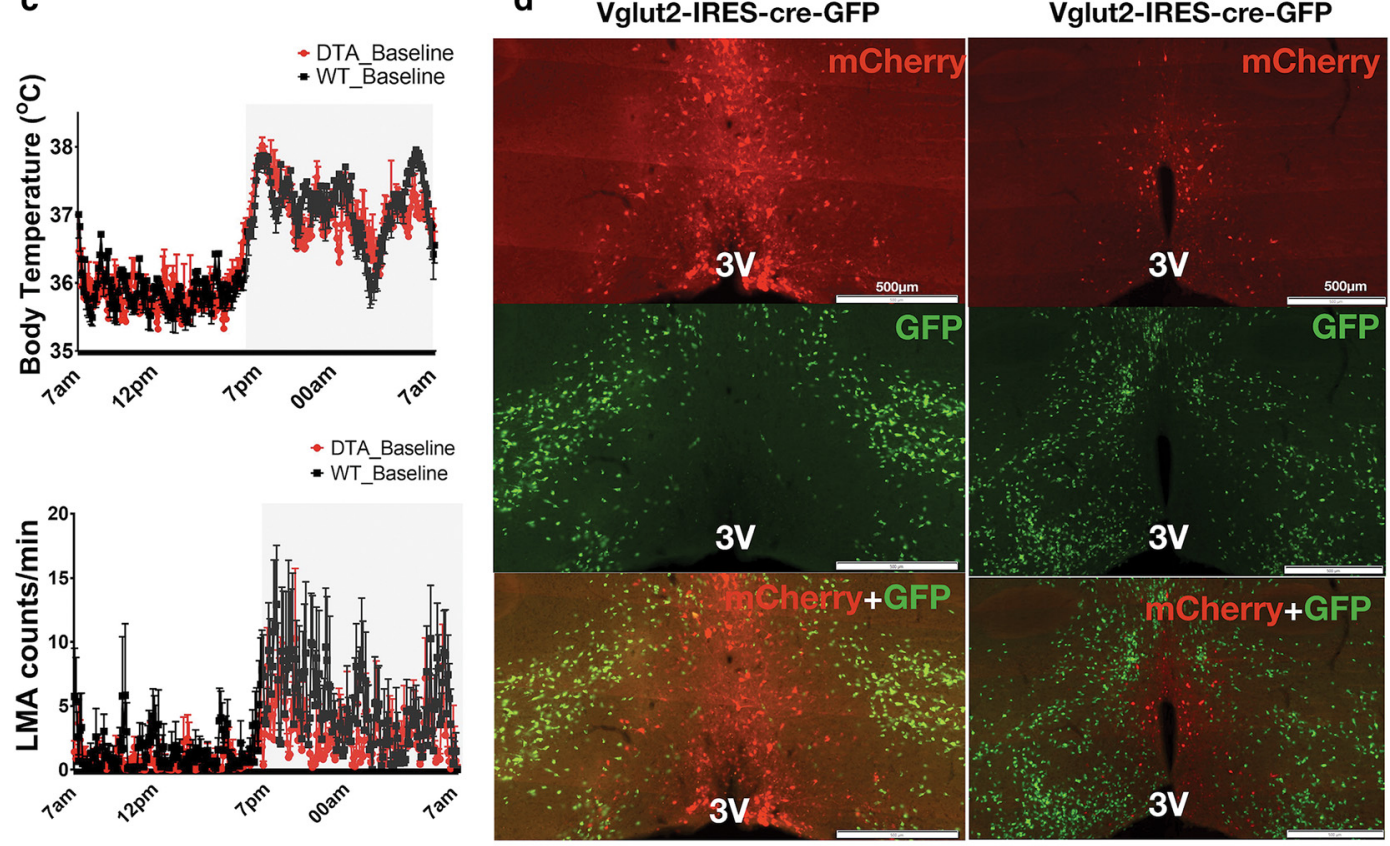

e

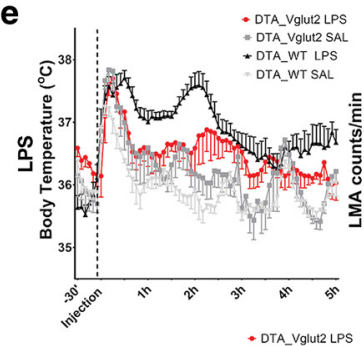

- DTA_Vglut LPS
- DTA_Vglut2 SAL

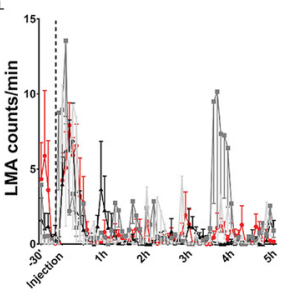

g $=$ DTA_Vglut SAL - OTA_WT LPS
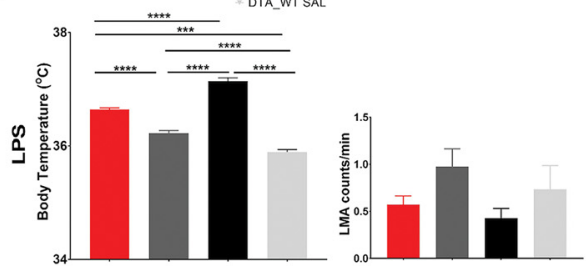

f

- DTA_Vlut2 STRESS
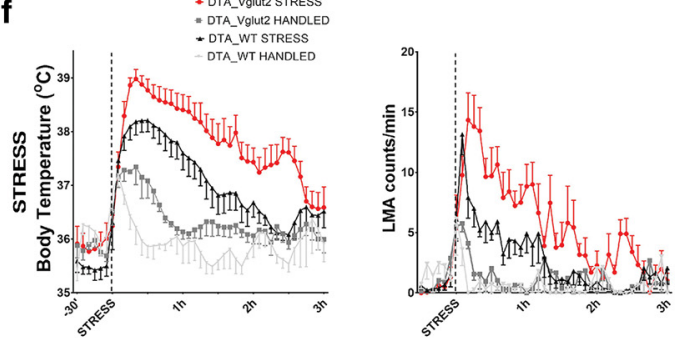

h

- DTA_Vglut2 STRESS DTA_Vglut2 HANDLED
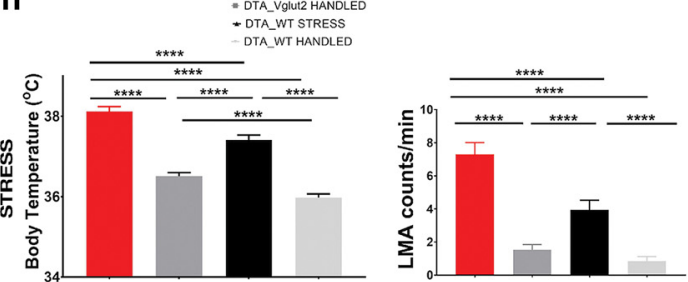

Figure 3. Ablation of $\mathrm{MnPO}^{\text {Vglut2 } 2}$ neurons eliminates fever induced by LPS and causes hyperthermia during behavioral stress. $\boldsymbol{a}$, Schematic figure of AAV-DTA injection in the MnPO of VGluT2-IRES-cre-GFP, VGluT2-IRES-cre, or WT mice. $\boldsymbol{b}$, A heatmap of the injection sites of all experimental mice. $\boldsymbol{c}$, Baseline Tb of VGluT2-Cre mice injected with AAV-DTA $(n=6)$ or WT mice $(n=$ 6) as control (DTA_VGluT2, $36.4 \pm 0.03^{\circ} \mathrm{C}$; DTA_WT, $36.59 \pm 0.04^{\circ} \mathrm{C}$; two-way ANOVA, $p=0.78$ during $24 \mathrm{~h}$ ) and baseline locomotor activity of the same mice (DTA_VGluT2, $1.7 \pm 0.1 \mathrm{cpm}$; DTA_WT, $3.0 \pm 0.16 \mathrm{cpm} ; p=0.80$, two-way ANOVA). $\boldsymbol{d}$, The top panels show the mCherry (red) expression in the non-VGluT2 neurons in the MnP0 outlining the AAV injection site, the middle panels show the remained VGluT2 neurons (green) in the POA region of a VGluT2-IRES-cre-GFP reporter mouse, and the bottom panels show the efficiency of AAV-DTA ablation of MnPO Vglut2 neurons in two coronal sections from the same VGluT2-IRES-cre-GFP reporter mouse (few if any green VGluT2 neurons are left in the field of red neurons that marks the AAV-DTA injection); no colocalization of VGluT2 neurons (green) and mCherry (red) was seen. $\boldsymbol{e}$, VGluT2-cre-DTA mice injected with LPS $(0.02 \mathrm{mg} / \mathrm{kg} ; n=6$; red) showed minimal fever responses compared with WT-DTA mice injected with same dose of LPS ( $n=6$; black). However, no difference was found in LMA patterns between groups treated with LPS. $f$, During the cage exchange stress protocol, VGluT2-cre-DTA mice (red) showed an increase in Tb compared with mice only handled (gray), but not transferred to a dirty cage, and a higher increase in Tb than WT-DTA subjected to same stress protocol (black). In addition, VGluT2-cre-DTA mice handled, but not transferred to a dirty cage, show a greater increase in Tb compared with WT-DTA handled mice (light gray). VGluT2-cre-DTA mice also show a greater increase in locomotion compared with WT-DTA mice during both handling and cage exchange stress. $\boldsymbol{g}$, During the peak of the fever response, VGluT2-cre-DTA mice show a Tb increase of $\sim 0.4^{\circ} \mathrm{C}$ compared with the same mice treated with saline $(n=6)$, while WT-DTA mice treated with LPS show an increase of $\sim 1.8^{\circ} \mathrm{C}$ compared with saline (DTA_VGluT2 (Figure legend continues.) 
hyperthermia induced by stress (Machado et al., 2018). During the first $2 \mathrm{~h}$ of the cage exchange protocol, VGluT2-cre-DTA mice showed an increase in $\mathrm{Tb}\left(\sim 1.65^{\circ} \mathrm{C}\right)$ compared with the same mice handled in the same way, but placed in their own cages, and a higher increase in $\mathrm{Tb}\left(\sim 0.7^{\circ} \mathrm{C}\right)$ when compared with WT-DTA mice subjected to the same stress protocol. In addition, VGluT2-cre-DTA mice handled, but not transferred to a dirty cage, show an increase in Tb compared with WT-DTA mice handled in the same way (DTA_VGluT2 STRESS, $38.15 \pm 0.12^{\circ} \mathrm{C}$; DTA_WT STRESS, $37.47 \pm 0.12^{\circ} \mathrm{C}$; DTA_VGluT2 Handled, $36.5 \pm 0.9^{\circ} \mathrm{C}$; DTA_WT HANDLED, $35.98 \pm 0.08$; $^{* * *} p<0.001$, ${ }^{* * * *} p<0.0001, F_{(4,445)}=280.8$ two-way ANOVA, followed by Bonferroni's post hoc test; $N=6$ DTA_VGluT2 STRESS; $N=6$ DTA_VGluT2 HANDLED; $N=6$ DTA_WT STRESS; and $N=3$ DTA_WT Handled). VGluT2-cre-DTA mice subjected to the cage exchange protocol also show an increase in LMA when compared with the same mice when handled or WT-DTA mice during the first $2 \mathrm{~h}$ of stress (DTA_VGluT2 STRESS, $7.39 \pm 0.7 \mathrm{cpm}$; DTA_WT STRESS, $3.8 \pm 0.5 \mathrm{cpm}$; DTA_VGluT2 HANDLED, $1.3 \pm 0.2 \mathrm{cpm}$; DTA_WT HANDLED, $0.8 \pm 0.2 \mathrm{cpm} ;{ }^{* * *} p<$ $0.001,{ }^{* * *} p<0.0001, F_{(3,425)}=89.78$ two-way ANOVA, followed by Bonferroni's post hoc test; $n=6$ DTA_VGluT2 STRESS; $n=6$ DTA_VGluT2 HANDLED; $n=6$ DTA_WT STRESS; $n=$ 3 DTA_WT HANDLED; Fig. $3 f, h)$. Thus, the MnPO ${ }^{\text {VGluT2 }}$ neurons are not required for hyperthermic stress responses, and deletion of MnPO ${ }^{\text {VGluT2 }}$ neurons does not prevent normal daily thermoregulation or other hyperthermic responses at $22^{\circ} \mathrm{C}$.

\section{Role of MnPO ${ }^{\text {Vat }}$ neurons during fever induced by LPS or stress-induced hyperthermia}

We then injected Cre-dependent AAV-DTA in the MnPO of Vgat-IRES-cre mice or Vgat-IRES-cre-GFP mice (Vgat-cre-DTA mice; DTA_Vgat), and WT littermates (WT-DTA; DTA_WT) as controls (Fig. $4 a$ ) to investigate the role of $\mathrm{MnPO}^{\text {Vgat }}$ neurons in regulating $\mathrm{Tb}$ and LMA responses to LPS injection and during cage exchange stress or thermal challenges.

Under baseline conditions, ablation of $\mathrm{MnPO}^{\text {Vgat }}$ neurons $(n=7$; Fig. $4 b, d)$ produced no change in Tb compared with intact WT-DTA mice $\left(n=7\right.$; DTA_Vgat, $36.71 \pm 0.03^{\circ} \mathrm{C}$; DTA_WT, $36.52 \pm 0.04^{\circ} \mathrm{C} ; p=0.95$, two-way ANOVA) or LMA (DTA_Vgat, $2.62 \pm 0.12 \mathrm{cpm}$; DTA_WT, $1.41 \pm 0.08 \mathrm{cpm} ; p=0.35$, two-way ANOVA) during $24 \mathrm{~h}$ of baseline recording (Fig. $4 c$ ).

In response to LPS injection $(0.02 \mathrm{mg} / \mathrm{kg})$, Vgat-cre-DTA

$\leftarrow$

(Figure legend continued.) $\quad$ LPS, $36.64 \pm 0.02^{\circ} \mathrm{C}$; DTA_VGluT2 saline, $36.23 \pm 0.04^{\circ} \mathrm{C}$; DTA_WT LPS, $37.14 \pm 0.06^{\circ} \mathrm{C}$; DTA_WT saline, $35.91 \pm 0.04^{\circ} \mathrm{C}$; ${ }^{* * *} p<0.001$, ${ }^{* * * *} p<$ $0.0001, F_{(3,355)}=102.2$, two-way ANOVA, followed by Bonferroni's post hoc test; $n=6$ DTA_VGluT2 LPS; $n=6$ DTA_VGluT2 saline; $n=6$ DTA_WT LPS; $n=3$ DTA_WT saline), but no changes were found in LMA. $\boldsymbol{h}$, During the first $2 \mathrm{~h}$ of the cage exchange protocol, VGluT2cre-DTA mice showed an increase in Tb compared with the same mice handled in the same way, but placed in their own cages, and a higher increase in Tb when compared with WT-DTA mice subjected to the same stress protocol. VGluT2-cre-DTA mice handled also show an increase in Tb compared with WT-DTA mice handled in the same way (DTA_VGluT2 STRESS, $38.15 \pm 0.12^{\circ} \mathrm{C}$; DTA_WT STRESS, $37.47 \pm 0.12^{\circ} \mathrm{C}$; DTA_VGluT2 Handled, $36.5 \pm 0.9^{\circ} \mathrm{C}$; DTA_WT HANDLED, $35.98 \pm 0.08 ;{ }^{* * *} p<0.001,{ }^{* * * *} p<0.00011, F_{(4,445)}=280.8$, two-way ANOVA, followed by Bonferroni's post hoc test; $n=6$ DTA_VGluT2STRESS; $n=6$ DTA_VGluT2 HANDLED; $N=6$ DTA_WT STRESS; and $N=3$ DTA_WT Handled). VGluT2-cre-DTA mice subjected to the cage exchange protocol also show an increase in locomotion when compared with the same mice when handled or WT-DTA mice during the first $2 \mathrm{~h}$ of stress (DTA_VGluT2 STRESS, 7.39 \pm 0.7 cpm; DTA_WT STRESS, $3.8 \pm 0.5 \mathrm{cpm}$; DTA_VGluT2 HANDLED, $1.3 \pm 0.2 \mathrm{cpm}$; DTA_WT HANDLED, $0.8 \pm 0.2 \mathrm{cpm} ;{ }^{* * *} p<0.001$, ${ }^{* * *} p<0.0001, F_{(3,425)}=89.78$ two-way ANOVA, followed by Bonferroni's post hoc test; $n=6$ DTA_VGluT2 STRESS; $n=6$ DTA_ VGluT2_HANDLED; $n=6$ DTA_WTSTRESS; $n=3$ DTA_WTHANDLED). 3V, Third ventricle. mice and WT mice injected with AAV-DTA showed similar fever responses when compared with Vgat-cre-DTA mice treated with saline [during the $2 \mathrm{~h}$ peak of $\mathrm{Tb}$ after initial hyperthermia induced by handling stress (i.e., 1-3 h after injection); DTA_Vgat LPS, $37.15 \pm 0.05^{\circ} \mathrm{C}$; DTA_WT LPS, $37.11 \pm 0.07^{\circ} \mathrm{C}$; DTA_Vgat saline, $36.08 \pm 0.04^{\circ} \mathrm{C} ;{ }^{* *} p<0.001,{ }^{* * *} p<0.0001, F_{(2,435)}=$ 147.8, two-way ANOVA, followed by Bonferroni's post hoc test; $n=7$ DTA_Vgat LPS; $N=7$ DTA_Vgat saline; and $N=7$ DTA_WT LPS]. Additionally, ablation of $\mathrm{MnPO}^{\text {Vgat }}$ neurons did not prevent the reduction of locomotor activity induced by LPS injection, a sign of sickness behavior, when compared with the same mice treated with saline, and as expected both groups injected with LPS show similar LMA responses (DTA_Vgat LPS, $0.24 \pm 0.03 \mathrm{cpm}$; DTA_WT LPS, $0.24 \pm 0.04 \mathrm{cpm}$; DTA_Vgat saline, $0.88 \pm 0.12 \mathrm{cpm} ;{ }^{* * *} p<0.001,{ }^{* * * *} p<0.0001, F_{(2,400)}=$ 17.07, two-way ANOVA; $N=7$ DTA_Vgat LPS; $N=7$ DTA_ Vgat saline; and $n=7$ DTA_WT LPS; Fig. $4 e, g)$.

These same Vgat-cre $(N=7)$ and WT $(N=6)$ mice injected with AAV-DTA were also subjected to cage exchange stress. The Vgat-cre-DTA mice show a slight increase in stress hyperthermia when compared with WT-DTA mice (DTA_Vgat STRESS, $37.47 \pm 0.12^{\circ} \mathrm{C}$; DTA_WT STRESS, $36.92 \pm 0.11^{\circ} \mathrm{C} ;{ }^{* * *} p<$ $0.001,{ }^{* * * *} p<0.0001, F_{(3,442)}=102.4$, two-way ANOVA, followed by Bonferroni's post hoc test), and both groups had stress hyperthermia compared with the Vgat-cre-DTA mice who were handled but put back in their own cages (producing a small and short-lived elevation of $\mathrm{Tb}$ ). However, no difference was found between the groups that were merely handled (DTA_Vgat HANDLED, $36.22 \pm 0.11^{\circ} \mathrm{C}$; DTA_WT HANDLED, $36.31 \pm$ $0.09^{\circ} \mathrm{C} ; p>0.99$, two-way ANOVA, followed by Bonferroni's post hoc test; $N=5$ Vgat-cre HANDLED; and $N=4$ DTA_WT HANDLED). Interestingly, during cage exchange stress, the ablation of $\mathrm{MnPO}^{\text {Vgat }}$ neurons induced an increase in LMA throughout the first $2 \mathrm{~h}$ of the stress protocol compared with WTDTA mice (DTA_Vgat STRESS, $5.66 \pm 0.6 \mathrm{cpm}$; DTA_WT STRESS, $4.05 \pm 0.57 \mathrm{cpm} ;{ }^{* *} p<0.001,{ }^{* * *} p<0.0001, F_{(3,450)}=$ 67.89, two-way ANOVA, followed by Bonferroni's post hoc test). However, no difference was found between the groups when the animals were only handled (DTA_Vgat HANDLED, $1.0 \pm 0.3 \mathrm{cpm}$; DTA_WT HANDLED, $1.36 \pm 0.3 \mathrm{cpm} ; p>0.99$, two-way ANOVA, followed by Bonferroni's post hoc test; $N=5$ Vgat-cre HANDLED; and $N=4$ DTA_WT HANDLED; Fig. $4 f, h)$.

\section{Both $\mathrm{MnPO}^{\text {VGluT2 }}$ and $\mathrm{MnPO}{ }^{\text {Vgat }}$ neurons play a role in warm and cold responses}

We habituated the same VGluT2-cre-DTA mice, Vgat-cre-DTA mice, and the DTA-injected WT littermates in an environmental chamber at $22^{\circ} \mathrm{C}$ for at least $3 \mathrm{~d}$ then exposed them to cold or warm conditions $\left(4^{\circ} \mathrm{C}\right.$, cold; $37^{\circ} \mathrm{C}$, warm) for $4 \mathrm{~h}$ (ZT4 to ZT9; Fig. $5 a$ ). During baseline (ZT4 to ZT9 at $22^{\circ} \mathrm{C}$ ), VGluT2-cre-DTA mice $(N=6)$ had similar Tb compared with WT-DTA mice $(n=$ 6; DTA_VGluT2, $35.72 \pm 0.02^{\circ} \mathrm{C}$; DTA_WT, $35.8 \pm 0.02^{\circ} \mathrm{C}$ 35.72; $p=0.06$ unpaired $t$ test). However, during exposure to the cold condition, VGluT2-cre-DTA mice $(N=6)$ show a small decrease in Tb compared with WT-DTA mice $(N=5)$, reflected in an increase of the area under the curve (AUC), which was calculated relative to the baseline (before cold), of the Tb responses when compared with WT-DTA mice (34.17 \pm 4.1 AUC, DTA_VGluT2; $17.68 \pm 2.7$, AUC DTA_WT; unpaired $t$ test, $p<$ 0.0001 ; Fig. $5 b)$. Although statistically significant, the difference between the groups was small $\left(\sim 0.2^{\circ} \mathrm{C}\right)$, and no difference was found between the LMA of the two groups. During the warm condition, VGluT2-cre-DTA mice $(n=6)$ showed a greater in- 
a

AAV-mCherry-flex-DTA

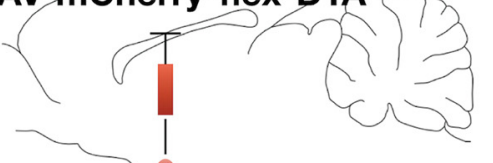

Vgat-IRES-cre-GFP mice Vgat-IRES-cre mice

C WT

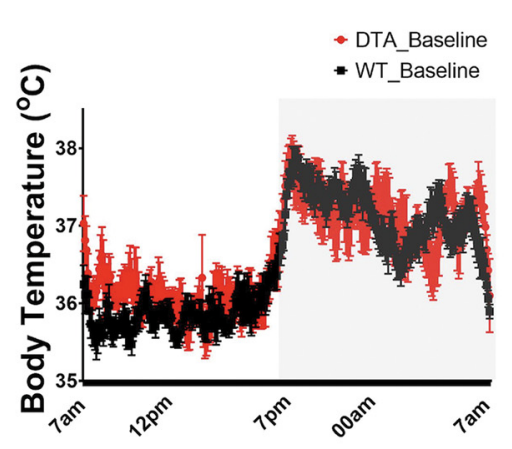

- DTA_Baseline

-WT_Baseline

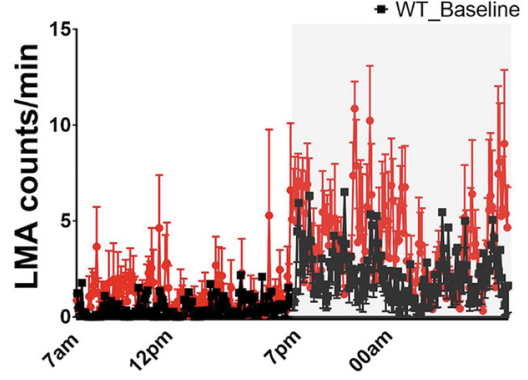

e - DTA_Vgat LPS
- DTA_Vgat SAL +DTA_WT LPS

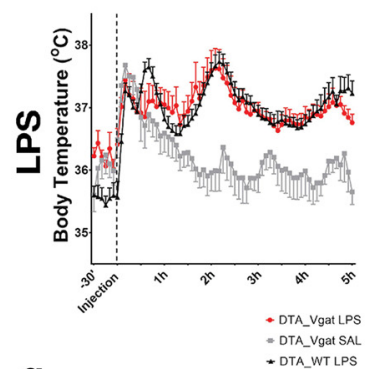

g

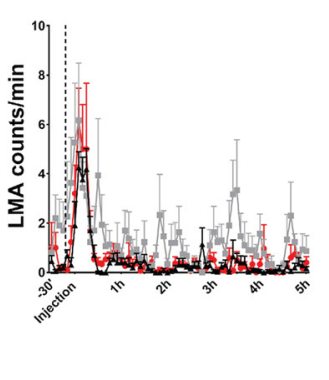

b Rostral

Caudal
Vgat-IRES-cre-GFP

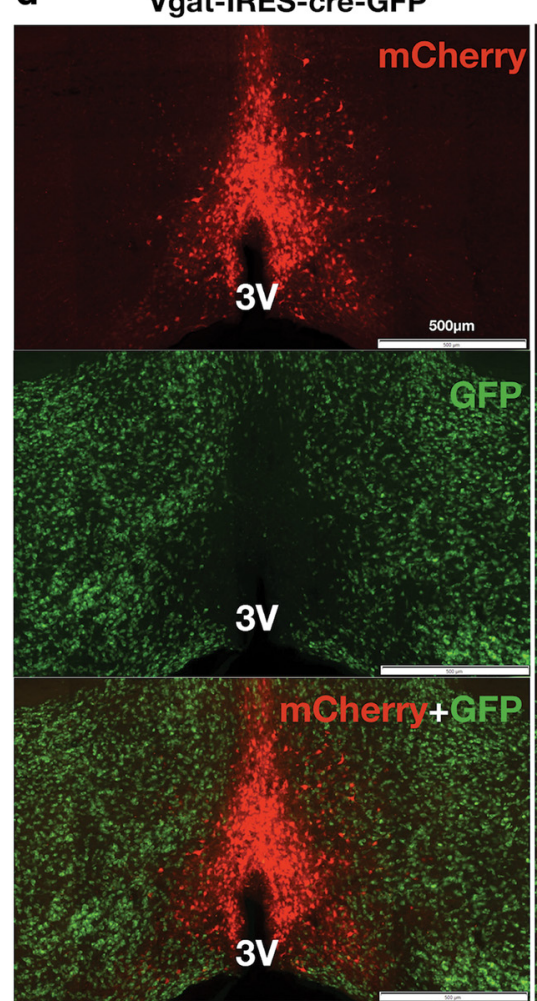

Vgat-IRES-cre-GFP

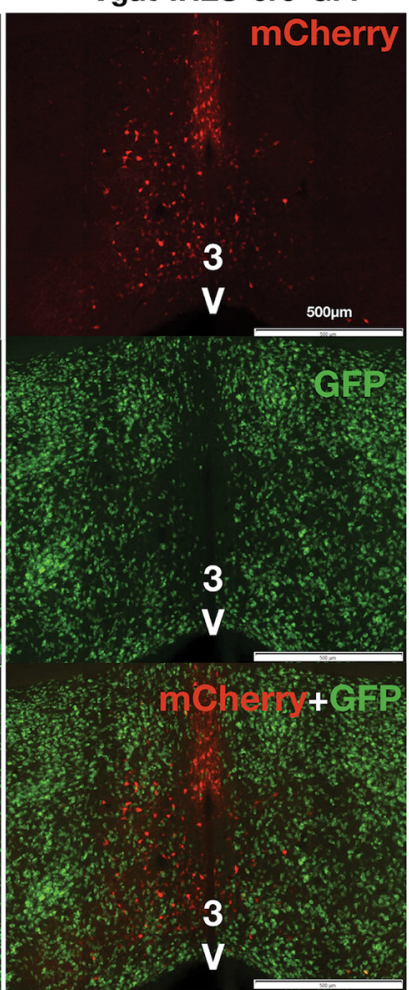

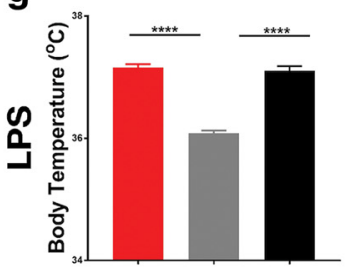

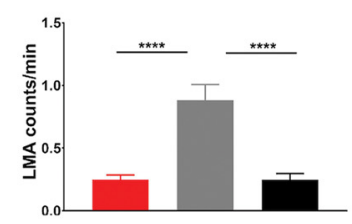

f

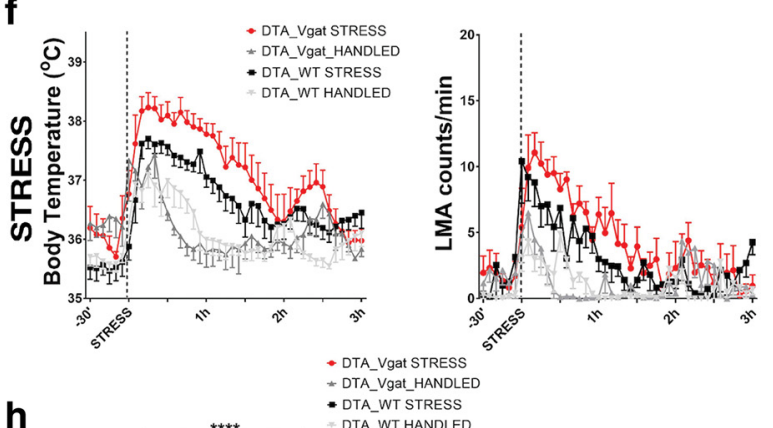

h
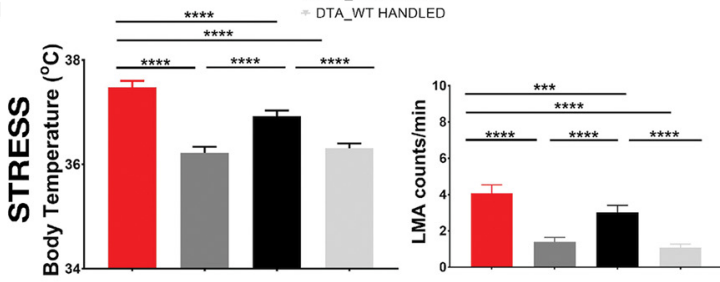

Figure 4. Ablation of MnPO ${ }^{\text {Vgat }}$ neurons does not prevent fever induced by LPS. $\boldsymbol{a}$, Schematic figure of AAV-DTA injection in the MnPO of Vgat-IRES-cre-GFP, Vgat-IRES-cre, or WT mice. $\boldsymbol{b}$, A heatmap of the injection sites of all experimental mice. $c$, There was no difference in baseline Tb of Vgat-Cre mice injected with AAV-DTA $(n=7)$ or WT mice $(n=7)$ as controls (DTA_Vgat, 36.71 \pm $0.03^{\circ} \mathrm{C}$; DTA_WT, $36.52 \pm 0.04^{\circ} \mathrm{C}$; two-way ANOVA, $\left.p=0.95\right)$ during $24 \mathrm{~h}$ and baseline locomotor activity of DTA_Vgat mice (DTA_Vgat, $2.62 \pm 0.12 \mathrm{cpm} ; \mathrm{DTA} \_W T, 1.41 \pm 0.08 \mathrm{cpm} ; p=0.35$, two-way ANOVA). $\boldsymbol{d}$, The top panels show the mCherry (red) expression in the non-Vgat neurons in the MnP0 of a Vgat-IRES-cre-GFP reporter mouse injected with the AAV-DTA, the central panels show the remained GABAergic (Vgat) neurons (green) in the POA region and the bottom panels show the efficiency of AAV-DTA to promote ablation of MnPO ${ }^{\mathrm{Vgat}}$ in two coronal sections from the same Vgat-IRES-cre-GFP reporter mouse; no colocalization of Vgat neurons (green) and mCherry (red) was seen. $\boldsymbol{e}$, In response to LPS injection ( $0.02 \mathrm{mg} / \mathrm{kg})$, Vgat-Cre-DTA mice and WT mice showed fever responses when compared with Vgat-cre-DTA mice treated with saline, but the two groups injected with LPS (Vgat-cre or WT) were not different from each other. Vgat-cre-DTA mice treated with LPS show a reduction of LMA when compared with the same mice treated with saline, but no difference was found in LMA comparing the two groups treated with LPS. $f$, The Vgat-cre-DTA mice show an increase in Tb and LMA during cage exchange stress when compared with WT mice subjected to the same protocol, but no difference was found between the (Figure legend continues.) 
crease in $\mathrm{Tb}$ of $\sim 0.8^{\circ} \mathrm{C}$ when compared with WT-DTA mice $(N=5 ; 103.4 \pm 3.3$, AUC DTA_VGluT2; $92.89 \pm 3.5$, AUC WT; unpaired $t$ test, $p=0.0006$; Fig. $5 c$ ), but no changes were observed in locomotion of these mice during heat stress. Consistent with the cage exchange result, these results suggest that during warming, the $\mathrm{MnPO}$ Vglut2 neurons help engage heat loss mechanisms.

When Vgat-cre-DTA mice were subjected to thermal challenges $\left(4^{\circ} \mathrm{C}\right.$, cold; $37^{\circ} \mathrm{C}$, warm) or during baseline (ZT4 to ZT9 at $22^{\circ} \mathrm{C}$ ) the ablation of $\mathrm{MnPO}{ }^{\text {Vgat }}$ neurons resulted in a slightly higher Tb than in WT-DTA animals. During the baseline condition, Vgat-cre-DTA $(N=7)$ show an increase in $\mathrm{Tb}$ of $\sim 0.3^{\circ} \mathrm{C}$ when compared with WT-DTA $(N=7$; DTA_Vgat, $36.15 \pm$ $0.02^{\circ} \mathrm{C}$; DTA_WT, $35.81 \pm 0.02^{\circ} \mathrm{C} ; p<0.0001$, unpaired $t$ test $)$.

During exposure to the cold condition, Vgat-cre-DTA mice $(N=6)$ show an $\sim 0.5^{\circ} \mathrm{C}$ higher $\mathrm{Tb}$ compared with WT mice $(n=$ 8; DTA_Vgat, $14.87 \pm 3.2$ AUC; DTA_WT, $19.43 \pm 2.6$, AUC DTA_WT; unpaired $t$ test, $p=0.007$; Fig. $5 d$ ), and during the warm condition these same Vgat-cre-DTA mice show a similar $\sim 0.5^{\circ} \mathrm{C}$ greater increase in $\mathrm{Tb}$ when compared with WT mice (76.09 \pm 2.38, DTA_Vgat AUC; $51.76 \pm 2.4$, WT AUC; unpaired $t$ test, $p<0.0001$; Fig. $5 e$ ). While these differences during thermal challenges were statistically significant, they are relatively small $\left(\sim 0.5^{\circ} \mathrm{C}\right)$, suggesting that $\mathrm{MnPO}{ }^{\text {Vgat }}$ neurons also play a modest role in heat loss. In addition, we did not observe changes in the locomotion pattern of Vgat-cre-DTA mice compared with WTDTA mice during cold or heat stress.

\section{EP3R-expressing MnPO neurons mediate fever responses}

To confirm the earlier observation by Lazarus et al. (2007) that the MnPO EP3R-expressing neurons are necessary for LPS fever, 10 mice in which loxP sites had been placed surrounding the first exon of the EP3R (Ptger $3 R^{\text {lox/lox }}$, which we will refer to as EP3R ${ }^{\text {flox }}$ mice here; Lazarus et al., 2007; Fig. 6a,b) received stereotaxic microinjections of a viral vector in the $\mathrm{MnPO}$ carrying the gene for Cre recombinase (AAV-iCre-2A-Venus, $N=5$ ) or AAV-GFP, as controls $(N=5$; Fig. $6 c, d)$. Our injection sites covered not only the MnPO, but also the OVLT and the VLPO. All these regions contain neurons that express EP3R, and these neurons in both the OVLT and rostral VLPO are continuous with and appear to rep-

\footnotetext{
$\leftarrow$

(Figure legend continued.) groups with handling. $\boldsymbol{g}$, During the peak of the fever response, no difference was found between Vgat-cre-DTA or WT-DTA groups treated with LPS; however, Vgat-cre-DTA mice show a greater increase in Tb (fever response) after LPS when compared with same mice treated with saline (DTA_Vgat LPS, $37.15 \pm 0.05^{\circ} \mathrm{C}$; DTA_WT LPS, $37.11 \pm$ $0.07^{\circ} \mathrm{C}$; DTA_Vgat saline, $36.08 \pm 0.04^{\circ} \mathrm{C} ;{ }^{* * *} p<0.001,{ }^{* * * *} p<0.0001, F_{(2,435)}=147.8$, two-way ANOVA, followed by Bonferroni's posthoctest; $n=7$ DTA_Vgat LPS; $n=7$ DTA_Vgat saline; and $n=7$ DTA_WT LPS). Vgat-cre-DTA mice and WT-DTA treated with LPS show similar patterns of LMA during the peak of fever response; however, Vgat-cre-DTA mice show a reduction of LMA when compared with the same mice treated with saline (DTA_Vgat LPS, $0.24 \pm$ $0.03 \mathrm{cpm}$; DTA_WT LPS, $0.24 \pm 0.04 \mathrm{cpm}$; DTA_Vgat saline, $0.88 \pm 0.12 \mathrm{cpm}$; ${ }^{* * *} p<0.001$, ${ }^{* * * *} p<0.0001, F_{(2,400)}=17.07$, two-way ANOVA; $n=7$ DTA_Vgat LPS; $n=7$ DTA_Vgat saline; and $n=7$ DTA_WT LPS). $\boldsymbol{h}$, During the first $2 \mathrm{~h}$ of stress, the ablation of MnP0 Vgat neurons also induced an increase in Tb and in LMA during cage exchange when compared with WT-DTA mice also subjected to the same stress protocol, but no difference was found between the groups with handling (DTA_Vgat STRESS, $37.56 \pm 0.12^{\circ} \mathrm{C}$; WT_STRESS, $37.0 \pm 0.1^{\circ} \mathrm{C}$; DTA_Vgat HANDLED, $36.19 \pm 0.1^{\circ} \mathrm{C}$; DTA_WT HANDLED, $36.31 \pm 0.09^{\circ} \mathrm{C}^{\text {; }}{ }^{* * *} p<0.001$, ${ }^{* * * *} p<0.0001, F_{(3,442)}=102.4$, two-way ANOVA, followed by Bonferroni's post hoc test; $n=$ 5 Vgat-cre; $n=6$ DTA_WT STRESS; and $n=4$ DTA_WT HANDLED; DTA_Vgat STRESS, $5.8 \pm$ $0.7 \mathrm{cpm}$; DTA_WT STRESS, $3.7 \pm 0.5 \mathrm{cpm}$; DTA_Vgat HANDLED, $1.0 \pm 0.3 \mathrm{cpm}$; DTA_WT HANDLED, $1.36 \pm 0.3 \mathrm{cpm}^{* * *} p<0.001,{ }^{* * *} p<0.0001, F_{(3,450)}=67.89$, two-way ANOVA, followed by Bonferroni's post hoc test; $n=5$ Vgat-cre; $n=6$ DTA_WT STRESS; and $n=4$ DTA_WT HANDLED). 3V, third ventricle.
}

resent an extension of the $\mathrm{MnPO}^{\mathrm{EP} 3 \mathrm{R}}$ population (Fig. 3, Oka et al., 2000; Fig. 2a, Lazarus et al., 2007). All mice received intraperitoneal injections of two different doses of LPS $(0.01 \mathrm{mg} / \mathrm{kg}$, low dose; and $1 \mathrm{mg} / \mathrm{kg}$, high dose), and saline as a control in random order at 1 week intervals, and were subjected to cage exchange stress, which causes behavioral hyperthermia (Machado et al., 2018).

Control mice, injected with AAV-GFP, showed a brief stress hyperthermia due to the handling during the injection of saline (Lazarus et al., 2007), followed by rapid return to baseline. After intraperitoneal injection of a low dose of LPS, the brief hyperthermia induced by handling was followed by a prolonged elevation of $\mathrm{Tb}$ (maximum $\Delta \mathrm{Tb}$ of $1.5 \pm 0.3^{\circ} \mathrm{C}$ at $150 \mathrm{~min}$ after LPS). The high dose of LPS initially shortened the handling hyperthermia response and was associated with a $\mathrm{Tb}$ below that of the saline-injected animals until $\sim 1.5 \mathrm{~h}$, when it was followed by an elevation of $\mathrm{Tb}$ (maximum $\Delta$ of $-1.19 \pm 0.3^{\circ} \mathrm{C} \sim 30$ min after LPS; $F_{(94,511)}=2.0$, two-way ANOVA, followed by Bonferroni's post hoc test; ${ }^{\star} \# p<0.0001, N=5$; Fig. $6 e$ ). When EP3R ${ }^{\text {flox }}$ mice injected with AAV-iCre-2A-Venus-2A-Cre were injected with a low dose of intraperitoneal LPS, the handling hyperthermia was shorter than in the animals injected with saline, suggesting an initial hypothermic phase $\left(\Delta \mathrm{Tb}\right.$ of $-1.04 \pm 0.4^{\circ} \mathrm{C} \sim 30 \mathrm{~min}$ after LPS), followed by complete lack of the fever response between 1.5 and $3 \mathrm{~h}$. After the high dose of LPS, the handling hyperthermia was also shortened and was followed by a prolonged period of profound hypothermia (maximum $\Delta \mathrm{Tb}$, $-3.7 \pm 0.4^{\circ} \mathrm{C}, \sim 150 \mathrm{~min}$ after LPS; $F_{(94,538)}=6.64$, two-way ANOVA, followed by Bonferroni's post hoc test; ${ }^{\star} \# p<0.0001$; $N=5$; Fig. $6 f$ ). These results confirm previous observations from Lazarus et al. (2007).

The mean baseline $\mathrm{Tb}$ of mice injected with AAV-iCre-2AVenus was slightly higher than controls injected with GFP [during both the light phase (Fig. $6 \mathrm{~g}$; EP3R ${ }^{\text {flox }}$ iCre-Venus, $36.39 \pm$ $0.02^{\circ} \mathrm{C}$; EP3R ${ }^{\text {flox }}$ GFP, $36.05 \pm 0.03^{\circ} \mathrm{C} ; p<0.0001$; unpaired $t$ test; $N=5$ each group) and the dark phase (EP3R ${ }^{\text {flox }}$ iCreVenus, $37.23 \pm 0.03^{\circ} \mathrm{C}$; EP3R ${ }^{\text {flox }}$ GFP, $37.05 \pm 0.02^{\circ} \mathrm{C} ; p<$ 0.0001 , unpaired $t$ test; $N=5$ each group), but no changes on baseline LMA were observed between these two groups. Similarly, EP3R ${ }^{\text {flox }}$ mice injected with AAV-iCre-2A-Venus show higher $\mathrm{Tb}$ after treatment with saline when compared with control mice injected with AAV-GFP (EP3R ${ }^{\text {flox }}$ iCre-Venus SAL, $36.62 \pm 0.02^{\circ} \mathrm{C} ; \mathrm{EP} \mathrm{R}^{\text {flox }} \mathrm{GFP}, 36.23 \pm 0.02^{\circ} \mathrm{C} ; p<0.0001$, unpaired $t$ test; $N=5$ each group; Fig. $7 h$ ). However, after two different doses of LPS, during the $2 \mathrm{~h}$ peak of Tb after initial hyperthermia induced by handling stress (i.e., 1-3 h after injection), EP3 ${ }^{\text {flox }}$ mice injected with $\mathrm{AAV}$-iCre-2A-Venus show lower $\mathrm{Tb}$ than controls (EP3R flox_iCre-Venus LPS $0.01 \mathrm{mg} / \mathrm{kg}$, $36.59 \pm 0.01^{\circ} \mathrm{C} ; \mathrm{EP} \mathrm{R}^{\text {flox }}$ GFP, $36.83 \pm 0.02^{\circ} \mathrm{C} ; p<0.0001$, unpaired $t$ test; $N=5$ each group; Fig. $6 i)$ and (EP3R ${ }^{\text {flox }}$ iCreVenus LPS, $1 \mathrm{mg} / \mathrm{kg} 33.97 \pm 0.13^{\circ} \mathrm{C}$; EP3R ${ }^{\text {flox }}$ GFP, $36.48 \pm$ $0.04^{\circ} \mathrm{C} ; p<0.0001$, unpaired $t$ test; $N=5$ each group; Fig. $6 j$ ), but both groups had similar $\mathrm{Tb}$ and related locomotor responses to cage exchange stress $\left(F_{\mathrm{LMA}(47,288)}=0.43\right.$. two-way ANOVA, followed by Bonferroni's post hoc test; $p=0.99$, two-way ANOVA; $N=4$ each group). This last result demonstrates that both groups had similar abilities to produce an increase in $\mathrm{Tb}$ during stress and provides evidence that the lack of a hyperthermic response after LPS injection in mice injected with AAV-iCre-2A-Venus is not due to a disruption in the mechanisms for heat production or conservation. 
a
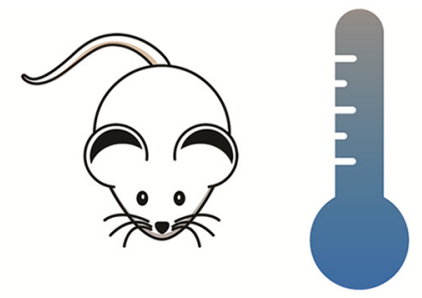

b

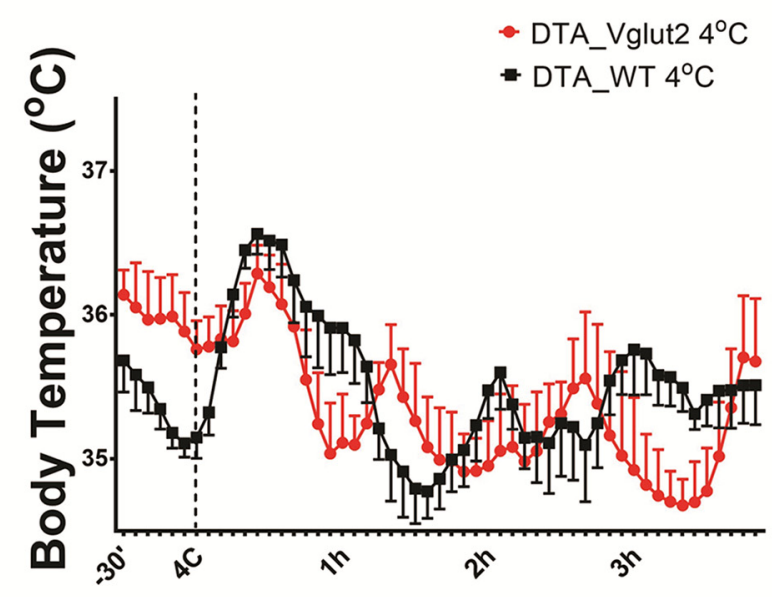

d

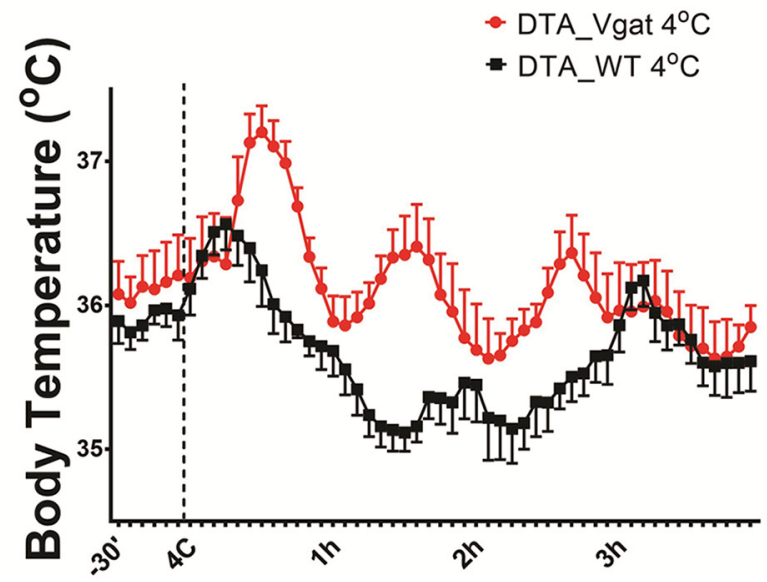

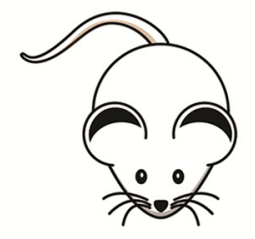

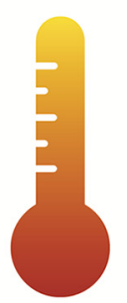

C

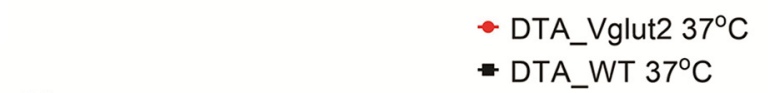

e
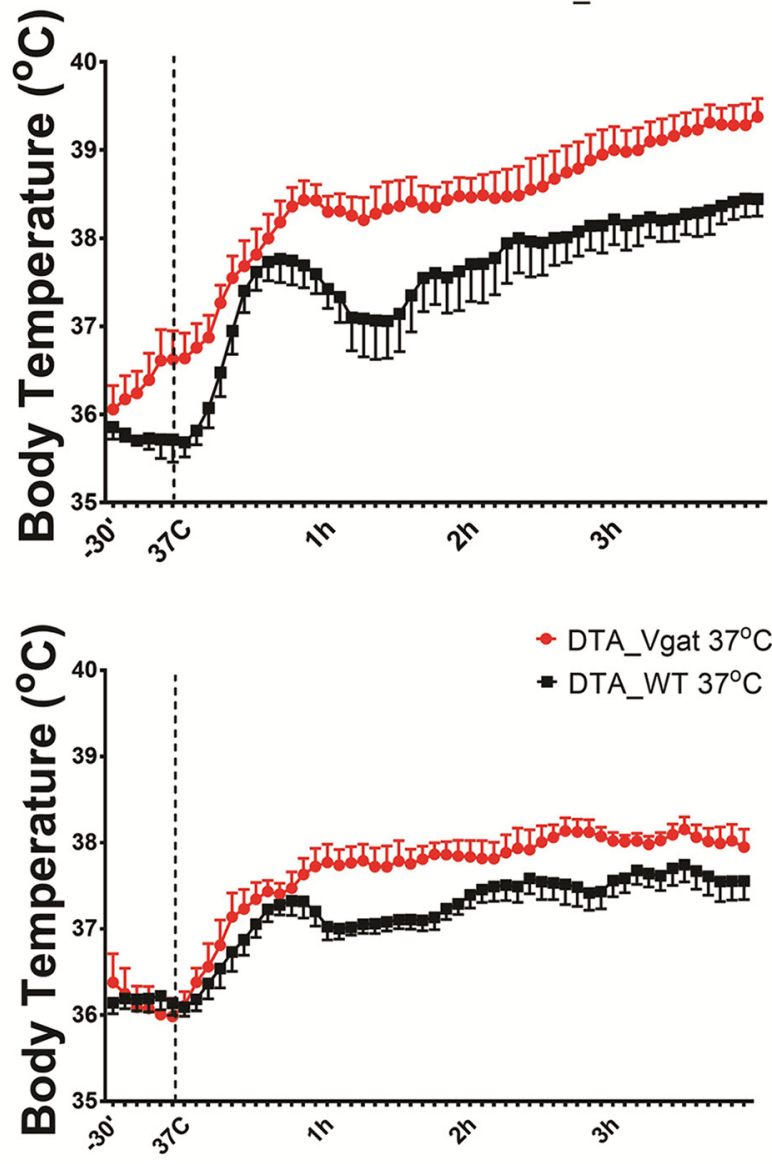

Figure 5. $\mathrm{MnPO} \mathrm{V}^{\text {Vglut2 } 2}$ and $\mathrm{MnPO} \mathrm{Vgat}^{\mathrm{Vgat}}$ neurons modulate cold and heat stress responses. $\boldsymbol{a}$, Schematic figure of exposure to a cold $\left(4^{\circ} \mathrm{C}\right)$ or warm $\left(37^{\circ} \mathrm{C}\right)$ environment. $\boldsymbol{b}$, During exposure to $4^{\circ} \mathrm{C}$, VGluT2-cre mice injected with DTA $(n=6)$ show an increase of the AUC of the Tb response compared with WT ( $n=5 ; 34.17 \pm 4.1$, DTA_VGluT2; 17.68 \pm 2.7 , DTA_WT; unpaired $t$ test of AUC, $p<$ $0.0001)$, but little effect in $\operatorname{Tb}\left(\sim 0.2^{\circ} \mathrm{C}\right)$. c, During exposure to $37^{\circ} \mathrm{C}$, the sameVGluT2-cre-DTA mice show a greater Tb than WT-DTA mice (103.4 \pm 3.3 , AUCDTA_VGluT2; $92.89 \pm 3.5$, AUC DTA_WT; unpaired $t$ test, $p=0.0006)$. The progressive increase in Tb suggests a failure of homeostatic cooling, rather than resetting the set point. $\boldsymbol{d}$, The ablation of MnP0 ${ }^{\mathrm{Vgat}}$ neurons $(n=6)$ resulted in a higher Tb response in Vgat-cre-DTA mice than in WT-DTA $(n=8)$ mice during exposure to cold $\left(4^{\circ} \mathrm{C}\right)$; a small overall increase of Tb was found in in Vgat-cre-DTA, while a reduction of Tb was observed in WT-DTA (14.87 \pm 3.2 , AUC DTA_Vgat; $19.43 \pm 2.6$, AUC DTA_WT; unpaired $t$ test, $p=0.007)$. $\boldsymbol{e}$, During the warm condition $\left(37^{\circ} \mathrm{C}\right)$, these same Vgat-cre-DTA mice show a greater increase in Tb when compared with WT-DTA mice (76.09 \pm 2.38 , DTA_Vgat AUC; $51.76 \pm 2.4$, DTA_WT AUC; unpaired $t$ test, $p<0.0001)$. However, Tb was relatively stable after the initial hour, suggesting that homeostatic thermoregulation remained. AUC was calculated relative to the baseline condition and used peaks above and under the values of baseline Tb.

EP3R-expressing glutamatergic neurons are required for LPS fever

To determine whether the fever response might be driven by the $\mathrm{MnPO}^{\mathrm{EP} 3 \mathrm{R}}$ neurons that express VGluT2 (96\% of the EP3Rexpressing MnPO neurons in our first experiment) or an EP3Rexpressing GABAergic $\left(\mathrm{Vgat}^{+}\right.$) population, we then crossed $\mathrm{EP} 3 \mathrm{R}^{\text {flox }}$ mice with VGluT2-IRES-cre mice to cause deletion of EP3R from VGluT2 neurons (VGluT2-CrexEP3R ${ }^{\text {flox }}$ mice); or with Vgat-IRES-cre mice to delete EP3R from Vgat neurons (Vgat-crexEP3R ${ }^{\text {flox }}$ mice; Fig. $7 a$ ). We then compared $\mathrm{Tb}$ in VGluT2-CrexEP3R ${ }^{\text {flox }}$ mice, Vgat-CrexEP3R ${ }^{\text {flox }}$ mice, and their wild-type littermates (WTxEP3R ${ }^{\text {flox }}$ ), which do not express Cre recombinase after LPS administration.

The WTxEP3R ${ }^{\text {flox }}$ animals injected with low-dose LPS (0.01 $\mathrm{mg} / \mathrm{kg}$ ) showed a typical handling hyperthermia followed by an elevation of Tb of $\sim 0.5^{\circ} \mathrm{C}$ at $150 \mathrm{~min}$. The VGluT2-CrexEP3R flox mice showed typical handling hyperthermia after saline injection, but after low-dose LPS, this was foreshortened so that the Tb was $1.44 \pm 0.4^{\circ} \mathrm{C}$ lower than the response to saline at $45 \mathrm{~min}$ after injection $\left(F_{(166,922)}=1.2\right.$, two-way ANOVA, followed by Bonferroni's post hoc test, ${ }^{*} p=0.04 ; n=5$ VGluT2-crexEP3R ${ }^{\text {flox }}$ LPS; $N=6$ VGluT2-CrexEP3R ${ }^{\text {flox }}$ saline; $N=3$ WTxEP3R $^{\text {flox }}$ LPS) 
a

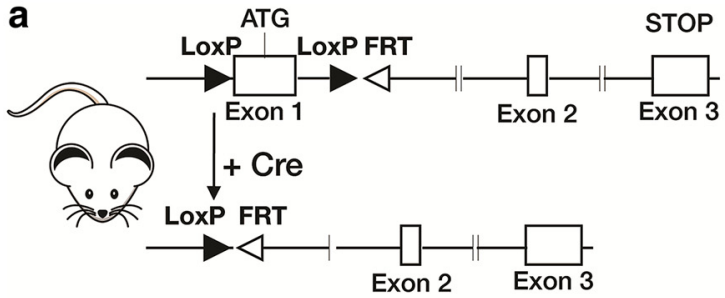

C

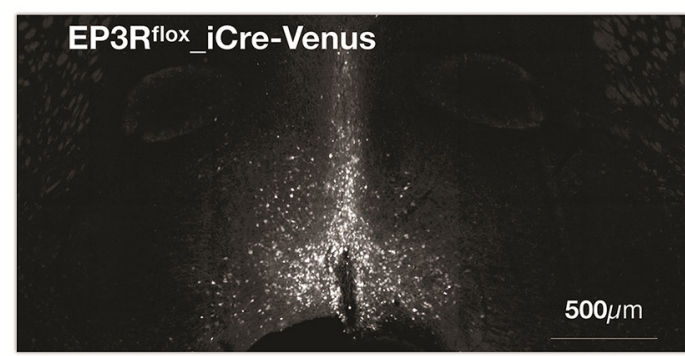

b

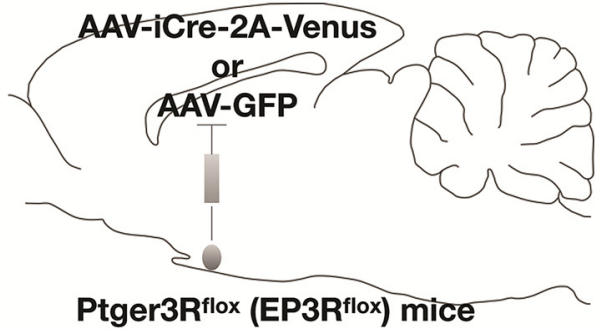

d

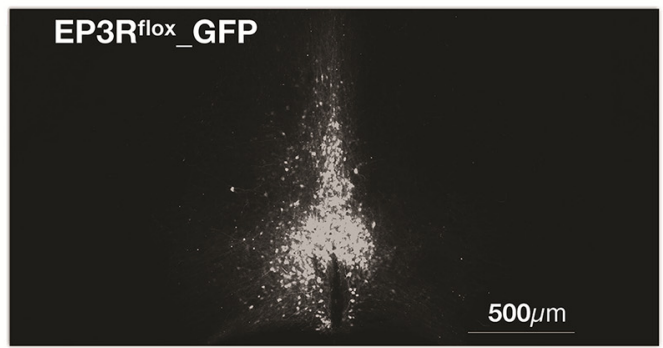

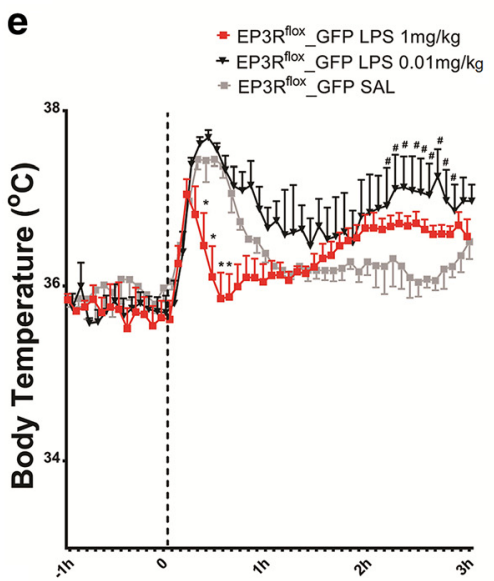
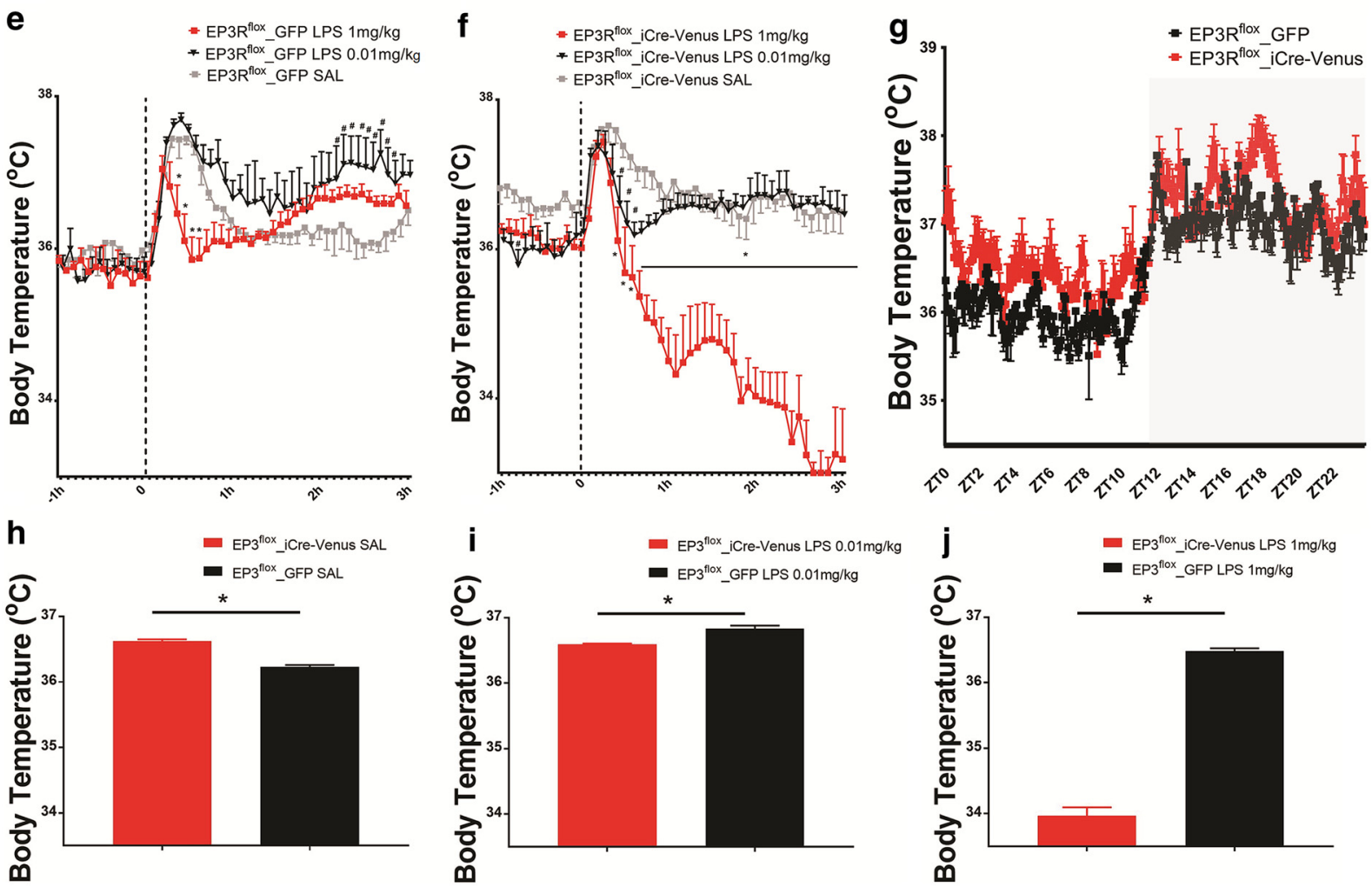

Figure 6. EP3R-expressing MnP0 neurons mediate fever responses. $\boldsymbol{a}$, Schematic figure of the genetic construct in EP3R ${ }^{\text {flox }}$ mice, where the loxP sites are flanked at exon 1 of the Ptger 3 gene, and the recombination in response to Cre recombinase. $\boldsymbol{b}$, Stereotaxic microinjections of a viral vector in the MnP0 carrying the gene for Cre recombinase, AAV-iCre-2a-Venus, or AAV-GFP AAV-iCre-2A-Venus, or AAV-GFP in male EP3R flox mice. $\boldsymbol{c}, \boldsymbol{d}$, Representative fluorescence image of AAV-iCre-Venus (c) or AAV-GFP expression in EP3R ${ }^{\text {flox }}$ mice $(\boldsymbol{d})$. $\boldsymbol{e}$, Control EP3R ${ }^{\text {flox }}$ mice, injected with AAV-GFP, showed a brief hyperthermic response to handling during the injection of saline, followed by a rapid return to baseline (gray line). However, the same mice injected with a low dose of LPS show a more prolonged elevation of Tb after the stress fever (black line; maximum $\Delta$ Tb of $1.5 \pm 0.3^{\circ} \mathrm{C}$ at $\sim 150$ min after intraperitoneal administration of LPS $0.01 \mathrm{mg} / \mathrm{kg}$ ). The high dose of LPS $(1 \mathrm{mg} / \mathrm{kg})$ initially shortened the handling hyperthermia response and was associated with a Tb below that of the saline-injected animals until at $\sim 1.5 \mathrm{~h}$ (red line), when it was followed by an elevation of $\mathrm{Tb}$ (maximum $\Delta$ of $-1.19 \pm 0.3^{\circ} \mathrm{C}$ at $\sim 30 \mathrm{~min}$ after intraperitoneal administration of LPS $1 \mathrm{mg} / \mathrm{kg} ; F_{(94.511)}$ $=2.0$, two-way ANOVA, followed by Bonferroni's post hoc test, $\left.{ }^{*} \# p<0.0001 ; n=5\right)$. $f$, When EP3R ${ }^{\text {flox }}$ mice injected with AAV-iCre-2A-Venus-2A-Cre were treated with a low dose of intraperitoneally administered LPS (black line), the handling hyperthermia was shorter than in the animals injected with saline (gray line), suggesting an initial hypothermic phase ( $\Delta \mathrm{Tb}$ of $-1.04 \pm 0.4^{\circ} \mathrm{C}$ at $\sim 30 \mathrm{~min}$ after intraperitoneal administration of LPS $0.01 \mathrm{mg} / \mathrm{kg}$ ), followed by complete lack of the fever response between 1.5 and $3 \mathrm{~h}$. After the high dose of LPS, the handling hypothermia was also shortened and was followed by a prolonged period of more profound hypothermia (maximum $\Delta \mathrm{Tb}-3.7 \pm 0.4^{\circ} \mathrm{C}, \sim 150 \mathrm{~min}$ after intraperitoneal administration of LPS $1 \mathrm{mg} / \mathrm{kg} ; F_{(94.538)}=6.64$, two-way ANOVA, followed by Bonferroni's post hoc test, $\left.{ }^{*} \# p<0.0001 ; n=5\right)$. $\boldsymbol{g}$, The baseline Tb of mice injected with AAV-iCre-Venus was higher than controls during the light phase (EP3R ${ }^{\text {flox }}$ i iCre-Venus $36.39 \pm 0.02^{\circ} \mathrm{C}$ vs EP3R ${ }^{\text {flox }}{ }_{-}$GFP $36.05 \pm 0.03^{\circ} \mathrm{C}, p<0.0001$ unpaired $t$ test, $N=5$ each group) and during the dark phase when analyzed separately (EP3R flox $\_$iCre-Venus, $37.23 \pm 0.03^{\circ} \mathrm{C} ; \mathrm{EP}_{3} \mathrm{R}^{\text {flox }}{ }_{-} \mathrm{GFP}, 37.05 \pm 0.02^{\circ} \mathrm{C} ; p<0.0001$, unpaired $t$ test; $N=5$ each group). $\boldsymbol{h}$, EP3 $\mathrm{R}^{\text {flox }}$ mice injected with AAV-iCre-2A-Venus show also higher Tb after treatment with saline when compared with control mice injected with AAV-GFP (EP3R ${ }^{\text {flox }}$ iCre-Venus SAL, $36.62 \pm 0.02^{\circ} \mathrm{C}$;

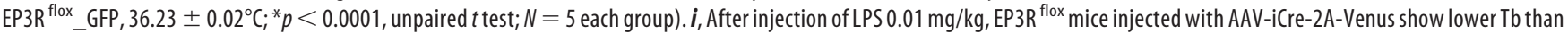
controls (EP3R ${ }^{\text {flox }}$ iCre-Venus LPS $0.01 \mathrm{mg} / \mathrm{kg}, 36.59 \pm 0.01^{\circ} \mathrm{C} ; \mathrm{EP} 3 \mathrm{R}^{\text {flox }}{ }_{-} \mathrm{GFP}, 36.83 \pm 0.02^{\circ} \mathrm{C} ;{ }^{*} p<0.0001$ unpaired $t$ test; $N=5$ each group). (Figure legend continues.) 
Figure $7 b$. A similar effect was found $\sim 45$ min after a dose of 0.1 $\mathrm{mg} / \mathrm{kg}$ LPS in VGluT2-CrexEP3R ${ }^{\text {flox }}$ mice, except that $\mathrm{Tb}$ at 45 min after LPS was as much as $2.27 \pm 0.4^{\circ} \mathrm{Cless}$ than same animals injected with saline. The higher dose of LPS $(0.1 \mathrm{mg} / \mathrm{kg})$, injected in WTxEP3R ${ }^{\text {flox }}$ littermates caused an increase in $\mathrm{Tb}$ (maximum $\Delta$ of $1.24 \pm 0.45^{\circ} \mathrm{C}$ at $\sim 150 \mathrm{~min}$ and $1.07 \pm 0.45^{\circ} \mathrm{C} 5 \mathrm{~h}$ after LPS injection; Fig. $7 c ; F_{(166,840)}=1.37$, two-way ANOVA, followed by Bonferroni's post hoc test, ${ }^{*} \# p=0.003, N=4$ VGluT2CrexEP3R ${ }^{\text {flox }}$ LPS; $n=6$ VGluT2-CrexEP3R ${ }^{\text {flox }}$ saline; and $n=3$ WTxEP3R ${ }^{\text {flox }}$ LPS).

By contrast, when LPS was injected in Vgat-CrexEP3R $\mathrm{R}^{\text {flox }}$ mice at low dose $(0.01 \mathrm{mg} / \mathrm{kg})$ and high dose $(0.1 \mathrm{mg} / \mathrm{kg})$ the responses were nearly indistinguishable from the WTxEP3R ${ }^{\text {flox }}$ littermates. In response to a low dose of LPS $(0.01 \mathrm{mg} / \mathrm{kg})$, we observed a maximum increase in $\mathrm{Tb}$ of $0.87 \pm 0.2^{\circ} \mathrm{C}$ in VgatCrexEP3R ${ }^{\text {flox }}$ mice compared with saline and the $\mathrm{WTxEP} 3 \mathrm{R}^{\text {flox }}$ littermates of Vgat-CrexEP3R ${ }^{\text {flox }}$ mice showed a similar fever response after LPS injection of $1.00 \pm 0.3^{\circ} \mathrm{C} \sim 120-150$ min after intraperitoneal administration of LPS (Fig. $7 d ; F_{(164,1078)}=1.35$, two-way ANOVA, followed by Bonferroni's post hoc test, ${ }^{\star} \# p=$

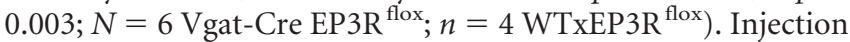
of LPS $0.1 \mathrm{mg} / \mathrm{kg}$ in Vgat-CrexEP3R ${ }^{\text {flox }}$ mice caused fever response of $1.28 \pm 0.3^{\circ} \mathrm{C}$ when compared with saline injection, and a similar response was found in $\mathrm{WTxEP} 3 \mathrm{R}^{\text {flox }}$ mice injected with the same dose of LPS $\left(1.13 \pm 0.3^{\circ} \mathrm{C}\right)$, both peaking $\sim 5 \mathrm{~h}$ after LPS injection (Fig. 5e; $F_{(164,1079)}=1.49$, two-way ANOVA, followed by Bonferroni's post hoc test, ${ }^{*} \# p=0.0002 ; N=6$ Vgat-

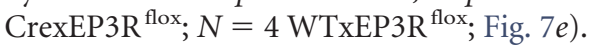

We also evaluated whether there were differences in the baseline $\mathrm{Tb}$ of the VGluT2-CrexEP3R ${ }^{\text {flox }}$ mice or Vgat-CrexEP3R ${ }^{\text {flox }}$ compared with their WTxEP3R ${ }^{\text {flox }}$ littermates, but no difference was found between the groups $\left(36.83 \pm 0.03^{\circ} \mathrm{C}\right.$, VGluT2crexEP3R ${ }^{\text {flox }} ; 36.67 \pm 0.04^{\circ} \mathrm{C}, \mathrm{WTxEP} 3 \mathrm{R}^{\text {flox }} ; N=6$, and $N=4$ respectively; $p=0.75$, two-way ANOVA).

As a control to make sure that the deletion of EP3R from all glutamate or GABA neurons in the CNS did not alter the ability of animals to produce an elevation of $\mathrm{Tb}$, we tested the stress hyperthermia response of the VGluT2-CrexEP3R flox and VgatCrexEP3 $\mathrm{R}^{\text {flox }}$ compared with WTxEP3R ${ }^{\text {flox }}$ mice in the cage exchange paradigm. Consistent with previous experiments using EP3R knock-out mice (Oka et al., 2003), EP3R selective deletion from glutamatergic or GABAergic cell types did not prevent or change stress-induced hyperthermia $\left(F_{(82,642)}=0.5\right.$, two-way ANOVA, followed by Bonferroni's post hoc test, $p=0.99 ; N=6$

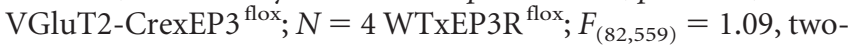
way ANOVA, followed by Bonferroni's post hoc test, $p=0.27$; $N=6$ Vgat-CrexEP3R $\left.^{\text {flox }} ; N=3 \mathrm{WTxEP} \mathrm{R}^{\text {flox }}\right)$.

Finally, to confirm that the EP3R deletion in these animals was complete and confined to the VGluT2 or Vgat population, we use in situ hybridization with a probe against exon 1 of the Ptger3 gene, which is surrounded by loxP sites. We observed that EP3R ${ }^{\text {flox }}$ mice (Fig. $7 f, i ; N=3$ ) or WT BL6/C57 mice (data not shown), and mice expressing Cre recombinase in Vgat neurons (Vgat-CrexEP3R ${ }^{\text {flox }}$ ) showed essentially identical patterns of mRNA labeling for EP3R mRNA in the MnPO, OVLT, and VLPO regions (Fig. $7 h, k ; N=4$ ). However, mice expressing Cre recombinase in glutamatergic neurons (VGluT2-CrexEP3R ${ }^{\text {flox }}$ mice)

(Figure legend continued.) $\quad \boldsymbol{j}, \mathrm{EP} 3 \mathrm{R}^{\text {flox } \_ \text {iCre-Venus mice showed hypothermia instead of fever }}$ after LPS $1 \mathrm{mg} / \mathrm{kg}$ (EP3R ${ }^{\text {flox }}$ iCre-Venus, $33.97 \pm 0.13^{\circ} \mathrm{C} ;$ EP3R ${ }^{\text {flox }}$ GFP, $36.48 \pm 0.04^{\circ} \mathrm{C}$; ${ }^{*} p<0.0001$, unpaired $t$ test; $N=5$ each group). $3 \mathrm{~V}$, Third ventricle. showed no expression of EP3R mRNA in the MnPO, OVLT, or VLPO (Fig. $7 g, j ; N=4$ ). On the other hand, EP3R mRNA expression was observed in other hypothalamic regions, such as the $\mathrm{DMH}$, ventromedial hypothalamus, lateral hypothalamus, and arcuate nucleus of three VGluT2-CrexEP3R ${ }^{\text {flox }}$ mice.

\section{Discussion}

In this study, we investigated the genetic identity of the EP3Rexpressing MnPO neurons that cause fever during an inflammatory response. We used in situ hybridization to demonstrate that $\mathrm{MnPO}^{\text {Vglut2 }}$ neurons express EP3R and a traditional retrograde tracer to show that $\mathrm{RPa}$-projecting $\mathrm{MnPO}$ neurons are mainly glutamatergic. We then demonstrated that cell-specific ablation of the $\mathrm{MnPO}^{\text {Vglut2 }}$ neurons precluded the febrile responses induced by LPS, and potentiated hyperthermia during behavioral stress or heat exposure. While the ablation of $\mathrm{MnPO}^{\text {Vgat }}$ neurons also caused a slight hyperthermia during behavioral, warm, or cold stress, it did not prevent LPS fever responses. Using conditional deletion of the EP3 prostaglandin receptor (EP3R ${ }^{\text {flox }}$ mice) in VGluT2-IRES-Cre and Vgat-IRES-Cre mice, we found that deleting EP3R from glutamatergic $\left(\mathrm{VGluT}^{+}{ }^{+}\right.$) but not GABAergic $\left(\mathrm{Vgat}^{+}\right.$) neurons prevented fever responses induced by intraperitoneal LPS. These results reveal that EP3R-expressing MnPO ${ }^{\text {Vglut2 }}$ neurons, but not $\mathrm{MnPO}^{\text {Vgat }}$ neurons, mediate fever responses. In addition, our results suggest that EP3R-expressing $\mathrm{MnPO}^{\text {Vglut2 }}$ neurons may modulate neurons in the RPa directly to produce fever during infectious and inflammatory conditions. However, because EP3 receptors are inhibitory and RPa neurons are thermogenic, we hypothesize that the $\mathrm{MnPO}^{\text {Vglut2 }}$ neurons that express EP3R are probably inhibited during a fever response, and innervate inhibitory interneurons in the $\mathrm{RPa}$, thus disinhibiting the RPa thermogenic neurons (Fig. 8). As shown in Figure 8, this is a fundamental shift in the standard model for thermoregulation and fever response.

Our interpretation that the $\mathrm{MnPO}{ }^{\text {Vglut2 }}$ neurons that express EP3R are glutamatergic and therefore excitatory is based on the premise that the neurotransmitter released by a neuron is dictated by its vesicular transporters. It is now clear that many of the cell types that express GAD in the preoptic area do not express Vgat, but instead express VGluT2 and presumably are excitatory (Moffitt et al., 2018). Another example is the melaninconcentrating hormone neurons in the lateral hypothalamus, which express GAD but not Vgat, and which do express VGluT2. Patch-clamp recordings from postsynaptic neurons indicate that these cells release glutamate, but not GABA (Chee et al., 2015). Similarly, tuberomammillary neurons that express histidine decarboxylase and GAD but not Vgat release histamine, but not GABA (Williams et al., 2014; Venner et al., 2019). The role of GAD in these neurons that lack Vgat is not clear, although GAD is part of a GABA-shunt metabolic pathway that cycles between glutamine and $\alpha$-keto-glutarate (Patel et al., 2005), and GABA may be playing a role in energy metabolism rather than neurotransmission.

Similarly, we previously showed that $\mathrm{MnPO}{ }^{\text {Vglut2 }}$ neurons innervate the DHA/DMH (Abbott et al., 2016), another key spot for producing fever responses to immune stimulation (Nakamura et al., 2005). The DHA/DMH also contains glutamatergic neurons that innervate the $\mathrm{RPa}$, and that play a key role in fever and stress-induced hyperthermia as well (Madden and Morrison, 2004; Machado et al., 2018). Thus, because the $\mathrm{MnPO}^{\text {Vglut2 }}$ neurons promote hypothermia, we hypothesize that they contact inhibitory interneurons in the $\mathrm{DMH}$, which then innervate the glutamatergic hyperthermic neurons in the DHA (Fig. 8). 
a
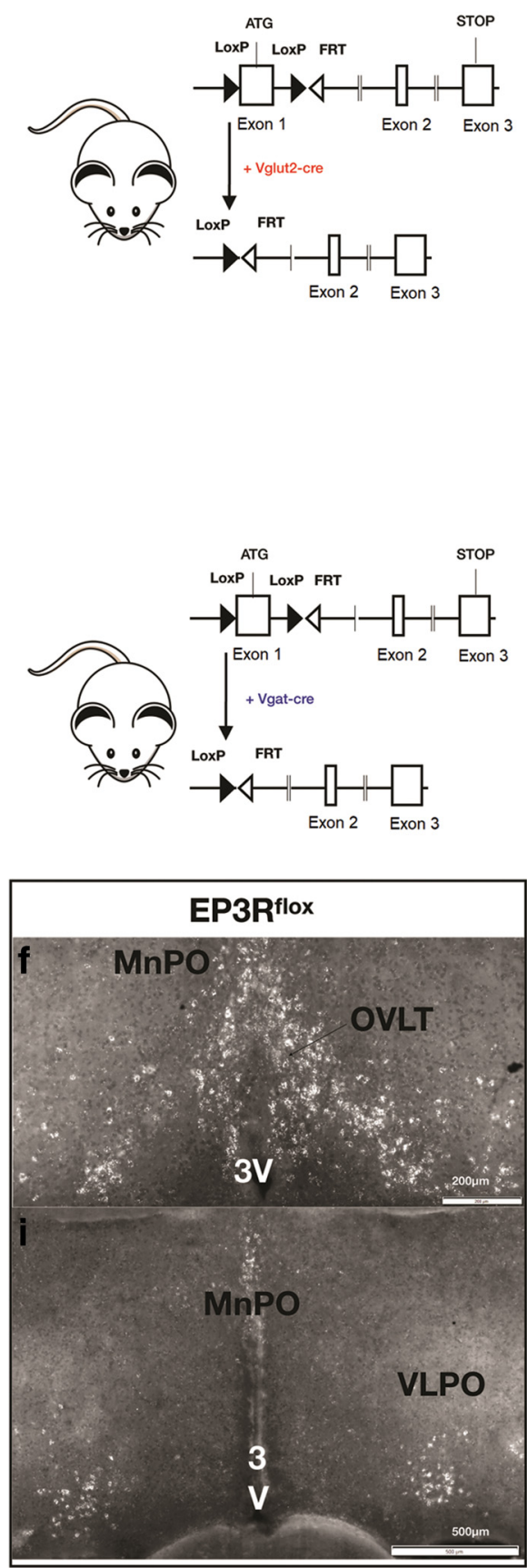

b
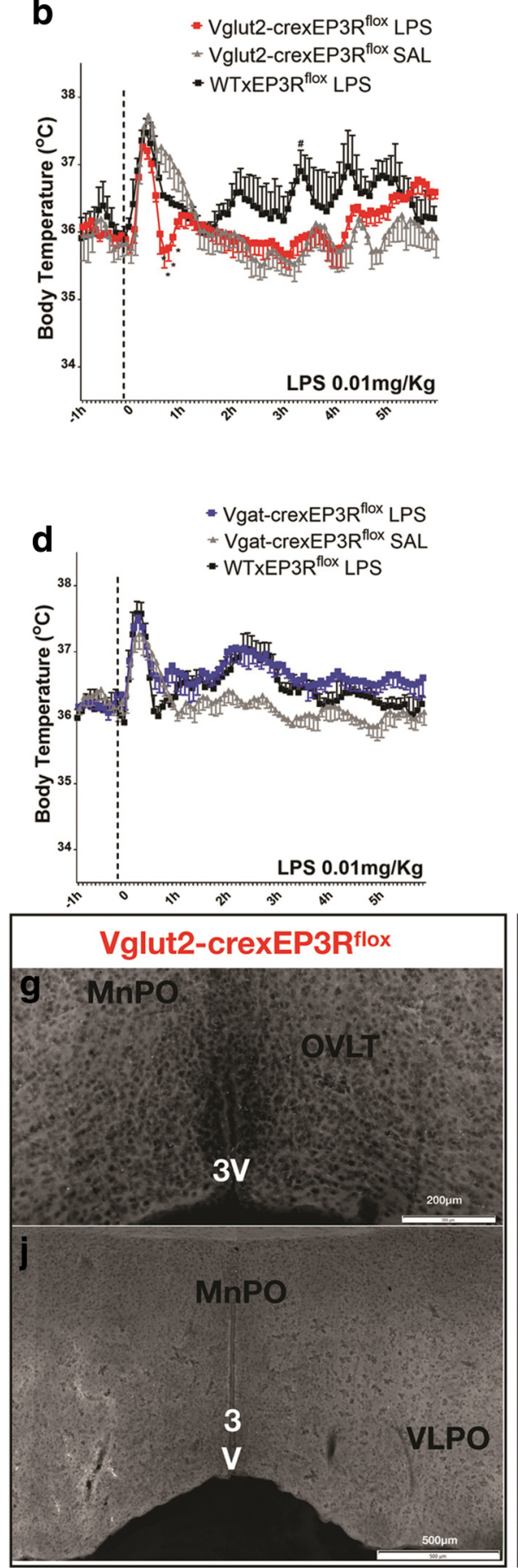

C

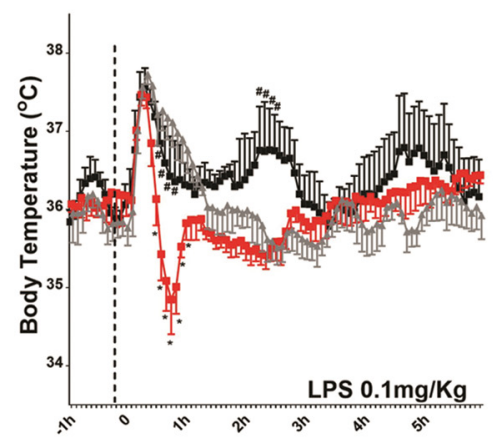

e
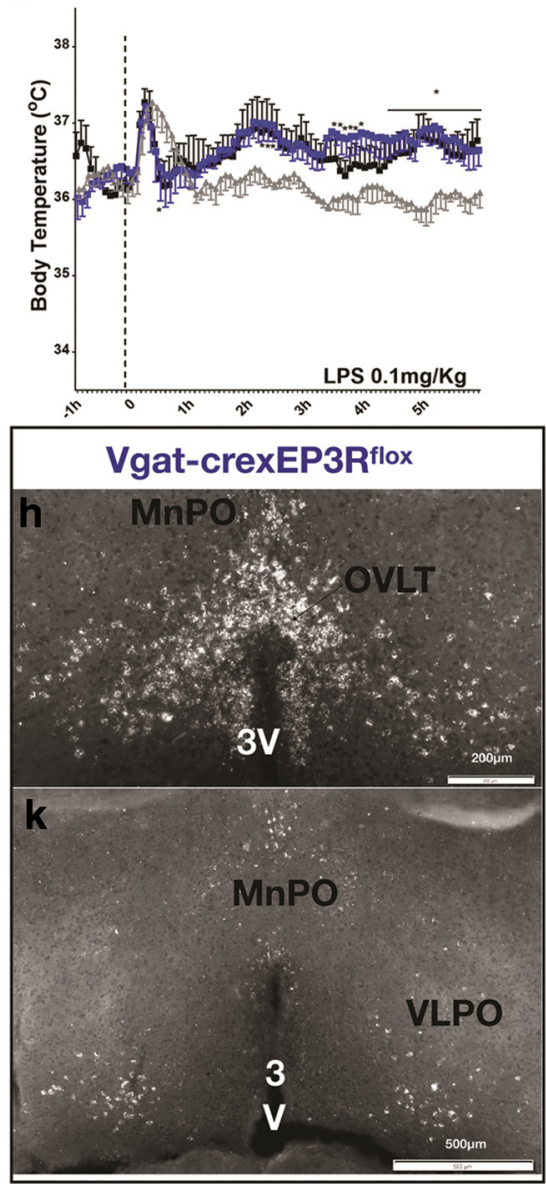

Figure 7. EP3R-expressing glutamatergic neurons are required for LPS fever. $\boldsymbol{a}$, Schematic figure of the genetic construct in EP $3 R^{\text {flox }}$ mice, where the loxP sites are flanked at exon 1 of the Ptger 3 gene, and the recombination in response to Cre. $\boldsymbol{b}$, The WTXEP3R ${ }^{\text {flox }}$ animals injected with low-dose LPS showed a typical stress fever from handling followed by an elevation of Tb of $\sim 0.5^{\circ} \mathrm{C}$ at 150 min (black line). The VGluT2-CrexEP3R ${ }^{\text {flox }}$ mice showed only a handling hyperthermia after saline injection (gray line), but after LPS this was foreshortened (red line) so that the Tb was $1.44 \pm 0.4^{\circ} \mathrm{C}$

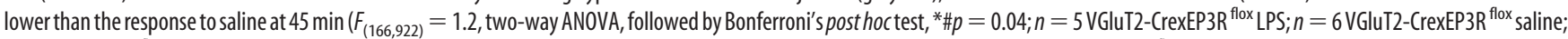
$n=3$ WTxEP3R $^{\text {flox }}$ LPS). At $1 \mathrm{~h}$ or later, the Tb was not different from saline injection (i.e., there was no fever response). c, VGluT2-CrexEP3R ${ }^{\text {flox }}$ mice injected with LPS $0.1 \mathrm{mg} / \mathrm{kg}$ show a rapid reduction of Tb at $45 \mathrm{~min}$ after LPS so that Tb was $2.27 \pm 0.4^{\circ} \mathrm{C}$ less than the same animals injected with saline, and failed to show a fever response to the LPS. The same dose of LPS $0.1 \mathrm{mg} / \mathrm{kg}$, injected into WTXEP3R ${ }^{\text {flox }}$ littermates caused an increase in $\mathrm{Tb}$ (maximum $\Delta$ of $1.24 \pm 0.45^{\circ} \mathrm{C}$ at $\sim 150 \mathrm{~min}$ and $1.07 \pm 0.45^{\circ} \mathrm{C}$ at $5 \mathrm{~h}$ after LPS injection; $F_{(166,840)}=1.37$, two-way ANOVA, followed by Bonferroni's post hoc test, ${ }^{*} \# p=0.003, n=4$ VGluT2-CrexEP3R ${ }^{\text {flox }}$ LPS; $n=6$ VGluT2-CrexEP3R ${ }^{\text {flox }}$ saline; and $n=3$ WTxEP3R ${ }^{\text {flox }}$ LPS). $d$, After injection of LPS at low dose (0.01 mg/kg), $V$ gat-CrexEP3R ${ }^{\text {flox }}$ mice (blue line) showed nearly a indistinguishable Tb fever response from the WTXEP $3 R^{\text {flox }}$ littermates (black line), a maximum increase in Tb of $0.87 \pm 0.2^{\circ} \mathrm{C}$ in $V$ gat-CrexEP $3 R^{\text {flox }}$ mice compared with saline (gray line) and the WTXEP3R ${ }^{\text {flox }}$ littermates mice show a similar fever response after LPS injection of $1.00 \pm 0.3^{\circ} \mathrm{C} ; F_{(164,1078)}=1.35$, two-way ANOVA, followed by Bonferroni's post hoc test, ${ }^{*} p=0.003 ; n=6$ Vgat-crexEP $3 R^{\text {flox }}$; and $n=4$ WTxEP3R ${ }^{\text {flox }}$.e, Injection of LPS $0.1 \mathrm{mg} / \mathrm{kg}$ in Vgat-CrexEP $3 \mathrm{R}^{\text {flox }}$ mice caused a fever response of $1.28 \pm 0.3^{\circ} \mathrm{C}$ when compared with saline injection, and a similar response was found in WTxEP3R ${ }^{\text {flox }}$ mice injected with same dose of $L P S\left(1.13 \pm 0.3^{\circ} \mathrm{C}\right)$, both peaking at $\sim 5 \mathrm{~h}$ after $L P S$ injection $\left(F_{(164,1079)}=1.49\right.$, two-way ANOVA, followed by Bonferroni's post hoc test, ${ }^{*} p=0.0002 ; n=6$ Vgat-CreXEP3R ${ }^{\text {flox }}$; and $n=4$ WTXEP3 $\left.{ }^{\text {flox }}\right)$. $\boldsymbol{f}$, $\boldsymbol{i}$, In situ hybridization reveals EP3R in the MnPO $(\boldsymbol{f})$ and VLPO (i) of EP3R ${ }^{\text {flox }}$ mice. $\boldsymbol{g}, \boldsymbol{h}, \boldsymbol{j}, \boldsymbol{k}$, Mice expressing (re recombinase in VGluT2 neurons (VGluT2-CrexEP3R ${ }^{\text {flox }}$ mice) do not show EP3R in the MnPO (g) or VLPO (j), while mice expressing Cre recombinase in Vgat neurons (Vgat-CrexEP3R ${ }^{\text {flox }}$ ) show normal mRNA labeling for EP3R mRNA in the MnPO (h) and VLPO (k). 3V, Third ventricle. 
a
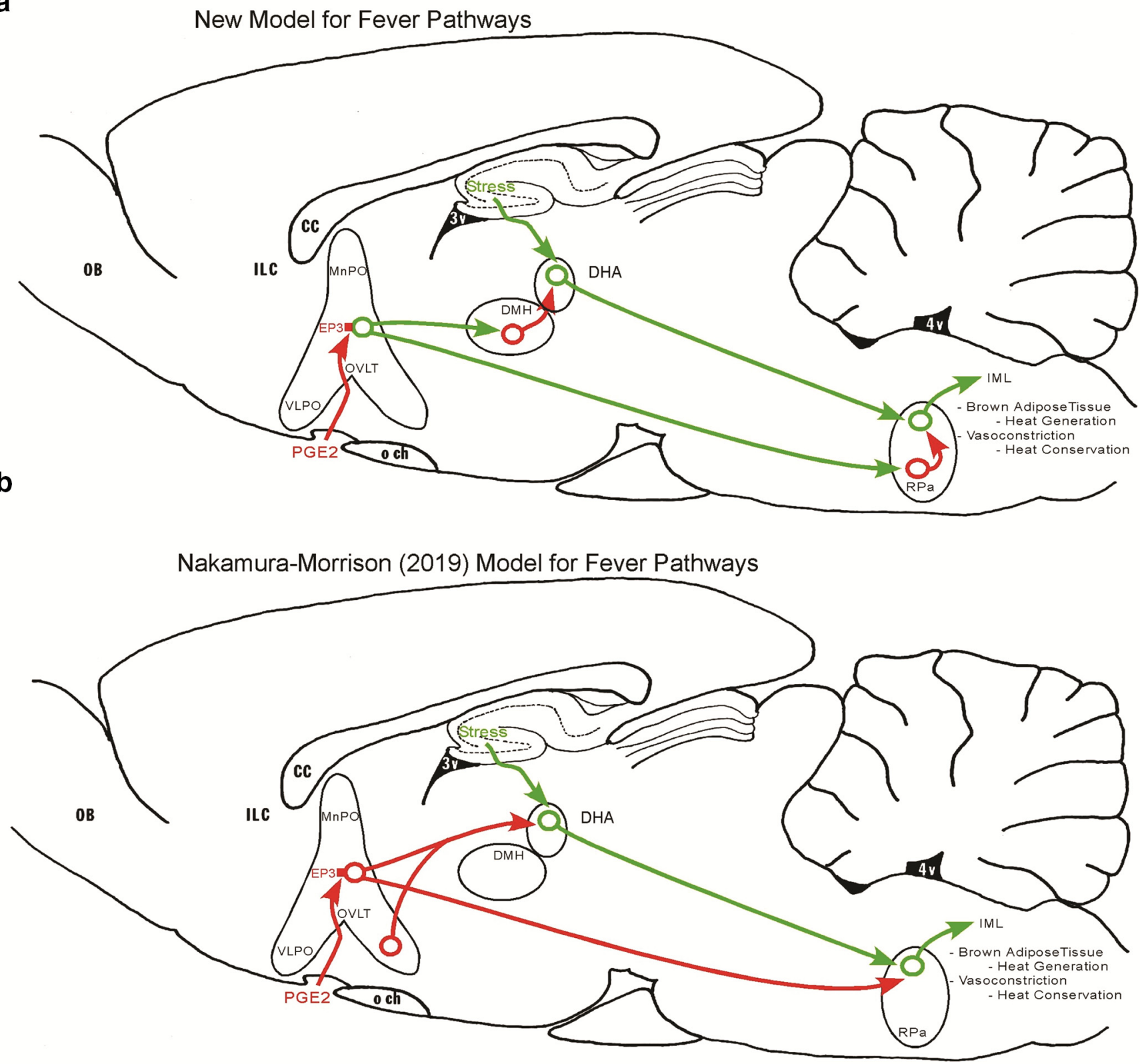

Figure 8. Schematic representation of the fever central pathways. $\boldsymbol{a}$, The new model for fever pathways is represented by the schematic figure at the top panel. During infectious and inflammatory conditions, PGE2 acts via EP3 inhibitory receptors (red) expressed in the MnPO ${ }^{\mathrm{Vglut} 2}$ and VLPO ${ }^{\text {Vglut2 } 2}$ neurons that project directly to DMH and RPa (green lines) to produce fever. We hypothesize that the $\mathrm{MnPO}^{\mathrm{Vglut} 2}$ neurons that express $\mathrm{EP} 3 \mathrm{R}$ are probably inhibited during a fever response, and innervate inhibitory interneurons in the $\mathrm{DMH}$ and $\mathrm{RPa}$ (red), thus disinhibiting the excitatory DHA and RPa thermogenic neurons. $\boldsymbol{b}$, The widely influential Morrison and Nakamura (2019) model hypothesized EP3R expression by MnPO ${ }^{\text {GABA }}$ neurons that directly disinhibit thermogenic excitatory DHA and RPa neurons (green) during fever responses. CC, corpus callosum; ILC, infralimbic cortex; IML, intermediolateral cell column; 0B, olfactory bulb; 0ch, Optic chiasm; OVLT, organum vasculosum of the lamina terminalis; $4 \mathrm{~V}$, fourth ventricle.

The cell-specific ablation of glutamatergic neurons in the MnPO region, which prevented LPS fever, did not change baseline Tb but surprisingly potentiated hyperthermia and hyperactivity caused by a stressful stimulus. This hyperthermic effect may be due to loss of $\mathrm{MnPO}$ thermoregulatory neurons that engage heat-loss mechanisms. Similarly, after ablation of $\mathrm{MnPO}^{\text {Vglut2 }}$ neurons, we observed hyperthermia during heat exposure, providing additional evidence that a population of $\mathrm{MnPO}^{\text {vglut2 }}$ neurons is active in a hot environment and cause compensatory heat loss (Morrison, 2016; Abbott and Saper, 2017, 2018; Zhao et al., 2017; Harding et al., 2018).

Although $\mathrm{MnPO}^{\text {Vgat }}$ neurons do not express EP3R, these neurons do appear to play a role in thermoregulation. The ablation of
$\mathrm{MnPO}^{\text {Vgat }}$ neurons did not prevent fever induced by LPS, but promoted a hyperthermic effect during cage exchange stress, and cold or warm conditions. Thus, $\mathrm{MnPO}^{\text {Vgat }}$ neurons, like $\mathrm{Mn}$ $\mathrm{PO}^{\text {Vglut2 }}$ neurons, appear to promote heat loss. However, few if any have EP3 receptors, and they do not appear to play a role in fever production.

The relatively modest effects on thermoregulation of loss of either the $\mathrm{MnPO}^{\text {Vglut2 }}$ or $\mathrm{MnPO}^{\text {Vgat }}$ neurons is in accord with our earlier study in rats showing that nonspecific ablations of the $\mathrm{MnPO}$ have little if any effect on baseline body temperature. There is a second population of preoptic neurons, in the dorsolateral preoptic area in rats, that projects to the DHA/DMH and to the $\mathrm{RPa}$, and only lesions of both the MnPO and the dorsolat- 
eral preoptic neurons, but not either alone, caused hyperthermia (of $\sim 1^{\circ} \mathrm{C}$; Yoshida et al., 2009). The dorsolateral preoptic neurons do not express EP3R, but their chemical phenotype and role in thermoregulatory circuitry remains to be studied.

Previous experiments performed in our laboratory have demonstrated that the selective loss of EP3Rs in the MnPO prevents fever responses to PGE2 and LPS (Lazarus et al., 2007). Using the same EP3 ${ }^{\text {flox }}$ mice and injections of a viral vector carrying genes for Cre (AAV-iCre-2A-Venus) to promote deletion of the EP3R from $\mathrm{MnPO}$ neurons, we have confirmed that EP3R expression in the $\mathrm{MnPO}$ is necessary for fever responses induced by low or $\mathrm{Tb}$ responses induced by a high dose of LPS. However, as expected, EP3R-expressing $\mathrm{MnPO}$ neurons are not required for stress-induced hyperthermia.

Similarly, the deletion of EP3R from glutamatergic neurons $\left(\mathrm{VGluT}^{+}{ }^{+}\right.$) also abolished fever responses for a range of doses of LPS, but did not prevent stress-induced hyperthermia. We showed here that $\sim 77 \%$ of the $\mathrm{MnPO}^{\mathrm{EP} 3 \mathrm{R}}$ neurons also express PACAP, and some may contain other potential neurotransmitters that may mediate a fever response to LPS. Thus, we do not know whether the release of glutamate, PACAP, or some other substance by the $\mathrm{MnPO}$ neurons expressing VGluT2 and EP3R is necessary to cause an LPS fever. We are currently investigating this question.

Although there are other CNS neurons that express EP3R, the EP3 receptors in those other regions are not capable of sustaining a LPS fever response in the absence of MnPO expression of EP3R or the ablation of $\mathrm{MnPO}{ }^{\text {Vglut2 }}$ neurons in mice, at least at $22^{\circ} \mathrm{C}$ [it is possible that other mechanisms (e.g., heat retention) may be more important at high ambient temperatures]. Hence, the loss of EP3R on the MnPO ${ }^{\text {Vglut2 }}$ neurons is the most parsimonious explanation for the lack of LPS fever in these animals. In accord with these physiological results, our anatomical investigation revealed that the EP3R is expressed exclusively in VGluT2 ${ }^{+}$neurons in the area at the anterior tip of the third ventricle, which is the critical site for mediating PGE2 fever responses (Scammell et al., 1996, 1998; Lazarus et al., 2007), including EP3R ${ }^{+}$neurons in the MnPO, OVLT, and VLPO. Our data, however, stand in contrast to the earlier hypothesized model by Morrison and Nakamura (2019). They have emphasized that $\mathrm{MnPO}^{\mathrm{EP} 3 \mathrm{R}}$ neurons that innervate the DMH/DHA and RPa express GAD, which led to the conclusion that $\mathrm{MnPO}^{\mathrm{EP} 3 \mathrm{R}}$ neurons are GABAergic (Nakamura et al., 2004; Nakamura et al., 2009; Morrison and Nakamura, 2019). In that model, MnPO ${ }^{\text {EP3R }}$ GABAergic neurons would act by tonic inhibition of neurons in downstream thermogenic regions, and PGE2-mediated inhibition of these neurons would release thermogenic responses (Fig. 8). In our study, we found that $\mathrm{MnPO}^{\mathrm{EP} 3 \mathrm{R}}$ neurons express VGluT2, but not Vgat, and therefore it is unlikely that $\mathrm{MnPO}^{\mathrm{EP} 3 \mathrm{R}}$ neurons have the cellular mechanisms to enable the synaptic release of GABA. The earlier results showing that POA neurons coexpress GAD and $\mathrm{EP} 3 \mathrm{R}$, and our observations of $\mathrm{MnPO}^{\mathrm{EP} 3 \mathrm{R}}$ neurons being excitatory cells are reconciled by the recent evidence showing that several types of $\mathrm{GAD}^{+}$neurons in the POA coexpress VGluT2, but not Vgat (Moffitt et al., 2018). Moreover, we found that $\mathrm{RPa}$-projecting MnPO neurons, a pathway thought to underlie critical mechanisms for fever generation (Nakamura et al., 2002), as well as RPa-projecting VLPO neurons are almost all glutamatergic, which suggests that EP3R-expressing $\mathrm{MnPO}^{\text {Vglut2 }}$ neurons may regulate the neural activity of RPa neurons during fever. This result presents a conundrum, as the fever response is thought to be due to the EP3R causing a reduction in cAMP levels and calcium entry into neurons (Negishi et al., 1995), and should there- fore be inhibitory. One possible explanation is that the EP3R may have excitatory isoforms, and that the $\mathrm{MnPO}^{\text {Vglut2 }}$ neurons may be activated by PGE2 to increase firing of RPa neurons or RPaprojecting DMH/DHA glutamatergic neurons during LPS fever (Machado et al., 2018; Piñol et al., 2018). This seems unlikely because direct activation of $\mathrm{MnPO}^{\text {Vglut2 }}$ neurons causes hypothermia (Abbott and Saper, 2017). Alternatively, the MnPO Vglut2 neurons may innervate inhibitory interneurons in the $\mathrm{RPa}$ and in the DHA/DMH, thus inhibiting neurons at both sites that contribute to the elevation of $\mathrm{Tb}$. In this model, the action of the EP3R would be to disinhibit the thermogenic and heat conservation mechanisms, thus producing a fever (Fig. 8).

Additionally, we found that VGluT2 mRNA expression in $\mathrm{MnPO}$ and VLPO neurons that project directly to the RPa shows a high degree of colocalization with PACAP. Tan et al. (2016) demonstrated that $\mathrm{MnPO}{ }^{\mathrm{PACAP}}$ neurons also express BDNF and are warm-responsive neurons that when activated promote a decrease in $\mathrm{Tb}$ through vasodilation and inhibition of brown adipose tissue thermogenesis (Tan et al., 2016). However, they reported that $69 \%$ of these neurons express GAD2, and therefore thought they were likely to be GABAergic. On the other hand, Moffitt et al. (2018) showed that at least six types of preoptic neurons that express BDNF and PACAP also express GAD2, and two of these also express GAD1, but only one BDNF/PACAP population expressed VGluT2. One of these populations, the e2 cell type, which expresses GAD2, was found in the ventral part of the $\mathrm{MnPO}$ and adjacent parts of the VLPO (i.e., precisely in the location of the population expressing the EP3R). Based on our results, it is probably the BDNF/PACAP e2 neurons that express VGluT2 and are glutamatergic that are part of the MnPO ${ }^{\mathrm{EP} 3 \mathrm{R}}$ glutamatergic population and participate in fever responses.

In conclusion, our findings represent the first step to redefine the central circuity in regulating inflammatory fever. Here we demonstrate that EP3R-expressing $\mathrm{MnPO}^{\text {Vglut2 }}$ neurons, but not $\mathrm{MnPO}^{\text {Vgat }}$ neurons, are necessary to produce fever, and that they probably do so by contacting inhibitory interneurons in the $\mathrm{DMH} / \mathrm{DHA}$ and $\mathrm{RPa}$. Thus, PGE2 would disinhibit their input to the thermogenic and heat conservation apparatus, and produce a fever.

\section{References}

Abbott SBG, Saper CB (2017) Median preoptic glutamatergic neurons promote thermoregulatory heat loss and water consumption in mice. J Physiol 595:6569-6583

Abbott SBG, Saper CB (2018) Role of the median preoptic nucleus in the autonomic response to heat-exposure. Temperature (Austin) 5:4-6.

Abbott SB, Machado NL, Geerling JC, Saper CB (2016) Reciprocal control of drinking behavior by median preoptic neurons in mice. J Neurosci 36:8228-8237.

Blomqvist A, Engblom D (2018) Neural mechanisms of inflammationinduced fever. Neuroscientist 24:381-399.

Chee MJ, Arrigoni E, Maratos-Flier E (2015) Melanin-concentrating hormone neurons release glutamate for feedforward inhibition of the lateral septum. J Neurosci 35:3644-3651.

Engström L, Ruud J, Eskilsson A, Larsson A, Mackerlova L, Kugelberg U, Qian H, Vasilache AM, Larsson P, Engblom D, Sigvardsson M, Jönsson JI, Blomqvist A (2012) Lipopolysaccharide-induced fever depends on prostaglandin E2 production specifically in brain endothelial cells. Endocrinology 153:4849-4861.

Eskilsson A, Matsuwaki T, Shionoya K, Mirrasekhian E, Zajdel J, Schwaninger M, Engblom D, Blomqvist A (2017) Immune-induced fever is dependent on local but not generalized prostaglandin E2 synthesis in the brain. J Neurosci 37:5035-5044.

Franklin KBJ, Paxinos G (2008) The Mouse Brain in Stereotaxic Coordinates, 3rd ed. Academic Press, San Diego, 256 pp.

Garami A, Steiner AA, Romanovsky AA (2018) Fever and hypothermia in systemic inflammation. Handb Clin Neurol 157:565-597. 
García-Bueno B, Serrats J, Sawchenko PE (2009) Cerebrovascular cyclooxygenase-1 expression, regulation, and role in hypothalamic-pituitaryadrenal axis activation by inflammatory stimuli. J Neurosci 29:12970-12981.

Guillery RW (2002) On counting and counting errors. J Comp Neurol 447:1-7.

Harding EC, Yu X, Miao A, Andrews N, Ma Y, Ye Z, Lignos L, Miracca G, Ba W, Yustos R, Vyssotski AL, Wisden W, Franks NP (2018) A neuronal hub binding sleep initiation and body cooling in response to a warm external stimulus. Curr Biol 28:2263-2273.e4.

Kaur S, Wang JL, Ferrari L, Thankachan S, Kroeger D, Venner A, Lazarus M, Wellman A, Arrigoni E, Fuller PM, Saper CB (2017) A genetically defined circuit for arousal from sleep during hypercapnia. Neuron 96:1153-1167.e5.

Kroeger D, Absi G, Gagliardi C, Bandaru SS, Madara JC, Ferrari LL, Arrigoni E, Münzberg H, Scammell TE, Saper CB, Vetrivelan R (2018) Galanin neurons in the ventrolateral preoptic area promote sleep and heat loss in mice. Nat Commun 9:4129.

Lazarus M, Yoshida K, Coppari R, Bass CE, Mochizuki T, Lowell BB, Saper CB (2007) EP3 prostaglandin receptors in the median preoptic nucleus are critical for fever responses. Nat Neurosci 10:1131-1133.

Machado NLS, Abbott SBG, Resch JM, Zhu L, Arrigoni E, Lowell BB, Fuller PM, Fontes MAP, Saper CB (2018) A glutamatergic hypothalamomedullary circuit mediates thermogenesis, but not heat conservation, during stress-induced hyperthermia. Curr Biol 28:2291-2301.e5.

Madden CJ, Morrison SF (2004) Excitatory amino acid receptors in the dorsomedial hypothalamus mediate prostaglandin-evoked thermogenesis in brown adipose tissue. Am J Physiol Regul Integr Comp Physiol 286: R320-R325.

Moffitt JR, Bambah-Mukku D, Eichhorn SW, Vaughn E, Shekhar K, Perez JD, Rubinstein ND, Hao J, Regev A, Dulac C, Zhuang X (2018) Molecular, spatial, and functional single-cell profiling of the hypothalamic preoptic region. Science 362:eaau5324. s

Morrison SF (2016) Central neural control of thermoregulation and brown adipose tissue. Auton Neurosci 196:14-24.

Morrison SF, Nakamura K (2019) Central mechanisms for thermoregulation. Annu Rev Physiol 81:285-308.

Nakamura K, Kaneko T, Yamashita Y, Hasegawa H, Katoh H, Ichikawa A, Negishi M (1999) Immunocytochemical localization of prostaglandin EP3 receptor in the rat hypothalamus. Neurosci Lett 260:117-120.

Nakamura K, Matsumura K, Hübschle T, Nakamura Y, Hioki H, Fujiyama F, Boldogköi Z, König M, Thiel HJ, Gerstberger R, Kobayashi S, Kaneko T (2004) Identification of sympathetic premotor neurons in medullary raphe regions mediating fever and other thermoregulatory functions. J Neurosci 24:5370-5380.

Nakamura K, Matsumura K, Kaneko T, Kobayashi S, Katoh H, Negishi M (2002) The rostral raphe pallidus nucleus mediates pyrogenic transmission from the preoptic area. J Neurosci 22:4600-4610.

Nakamura Y, Nakamura K, Matsumura K, Kobayashi S, Kaneko T, Morrison SF (2005) Direct pyrogenic input from prostaglandin EP3 receptorexpressing preoptic neurons to the dorsomedial hypothalamus. Eur J Neurosci 22:3137-3146.

Nakamura Y, Nakamura K, Morrison SF (2009) Different populations of prostaglandin EP3 receptor-expressing preoptic neurons project to two fever-mediating sympathoexcitatory brain regions. Neuroscience 161: $614-620$.

Negishi M, Sugimoto Y, Ichikawa A (1995) Prostaglandin E receptors. J Lipid Mediat Cell Signal 12:379-391.

Oka T, Oka K, Scammell TE, Lee C, Kelly JF, Nantel F, Elmquist JK, Saper CB (2000) Relationship of EP(1-4) prostaglandin receptors with rat hypothalamic cell groups involved in lipopolysaccharide fever responses. J Comp Neurol 428:20-32.

Oka T, Oka K, Saper CB (2003) Contrasting effects of E type prostaglandin (EP) receptor agonists on core body temperature in rats. Brain Res 968:256-262.
Patel AB, de Graaf RA, Mason GF, Rothman DL, Shulman RG, Behar KL (2005) The contribution of GABA to glutamate/glutamine cycling and energy metabolism in the rat cortex in vivo. Proc Natl Acad Sci U S A 102:5588-5593.

Piñol RA, Zahler SH, Li C, Saha A, Tan BK, Sǩop V, Gavrilova O, Xiao C, Krashes MJ, Reitman ML (2018) Brs3 neurons in the mouse dorsomedial hypothalamus regulate body temperature, energy expenditure, and heart rate, but not food intake. Nat Neurosci 21:1530-1540.

Saper CB, Breder CD (1994) The neurologic basis of fever. N Engl J Med 330:1880-1886

Scammell TE, Elmquist JK, Griffin JD, Saper CB (1996) Ventromedial preoptic prostaglandin E2 activates fever-producing autonomic pathways. J Neurosci 16:6246-6254.

Scammell TE, Griffin JD, Elmquist JK, Saper CB (1998) Microinjection of a cyclooxygenase inhibitor into the anteroventral preoptic region attenuates LPS fever. Am J Physiol 274:R783-R789.

Song K, Wang H, Kamm GB, Pohle J, Reis FC, Heppenstall P, Wende H, Siemens J (2016) The TRPM2 channel is a hypothalamic heat sensor that limits fever and can drive hypothermia. Science 353:1393-1398.

Tan CL, Cooke EK, Leib DE, Lin YC, Daly GE, Zimmerman CA, Knight ZA (2016) Warm-sensitive neurons that control body temperature. Cell 167:47-59.e15.

Tanaka M, McKinley MJ, McAllen RM (2011) Preoptic-raphe connections for thermoregulatory vasomotor control. J Neurosci 31:5078-5088.

Tanaka M, McKinley MJ, McAllen RM (2013) Role of an excitatory preoptic-raphe pathway in febrile vasoconstriction of the rat's tail. Am J Physiol Regul Integr Comp Physiol 305:R1479-R1489.

Tang W, Ehrlich I, Wolff SB, Michalski AM, Wölfl S, Hasan MT, Lüthi A, Sprengel R (2009) Faithful expression of multiple proteins via 2Apeptide self-processing: a versatile and reliable method for manipulating brain circuits. J Neurosci 29:8621-8629.

Todd WD, Fenselau H, Wang JL, Zhang R, Machado NL, Venner A, Broadhurst RY, Kaur S, Lynagh T, Olson DP, Lowell BB, Fuller PM, Saper CB (2018) A hypothalamic circuit for the circadian control of aggression. Nat Neurosci 21:717-724.

Ushikubi F, Segi E, Sugimoto Y, Murata T, Matsuoka T, Kobayashi T, Hizaki H, Tuboi K, Katsuyama M, Ichikawa A, Tanaka T, Yoshida N, Narumiya S (1998) Impaired febrile response in mice lacking the prostaglandin E receptor subtype EP3. Nature 395:281-284.

Vasilache AM, Andersson J, Nilsberth C (2007) Expression of PGE2 EP3 receptor subtypes in the mouse preoptic region. Neurosci Lett 423: $179-183$.

Venner A, Mochizuki T, De Luca R, Anaclet C, Scammell TE, Saper CB, Arrigoni E, Fuller PM (2019) Reassessing the role of histaminergic tuberomammillary neurons in arousal control. J Neurosci 39:8929-8939.

Williams RH, Chee MJ, Kroeger D, Ferrari LL, Maratos-Flier E, Scammell TE, Arrigoni E (2014) Optogenetic-mediated release of histamine reveals distal and autoregulatory mechanisms for controlling arousal. J Neurosci 34:6023-6029.

Yoshida K, Nakamura K, Matsumura K, Kanosue K, König M, Thiel HJ, Boldogköi Z, Toth I, Roth J, Gerstberger R, Hübschle T (2003) Neurons of the rat preoptic area and the raphe pallidus nucleus innervating the brown adipose tissue express the prostaglandin E receptor subtype EP3. Eur J Neurosci 18:1848-1860.

Yoshida K, Li X, Cano G, Lazarus M, Saper CB (2009) Parallel preoptic pathways for thermoregulation. J Neurosci 29:11954-11964.

Yu S, Qualls-Creekmore E, Rezai-Zadeh K, Jiang Y, Berthoud HR, Morrison CD, Derbenev AV, Zsombok A, Münzberg H (2016) Glutamatergic preoptic area neurons that express leptin receptors drive temperaturedependent body weight homeostasis. J Neurosci 36:5034-5046.

Zhao ZD, Yang WZ, Gao C, Fu X, Zhang W, Zhou Q, Chen W, Ni X, Lin JK, Yang J, Xu XH, Shen WL (2017) A hypothalamic circuit that controls body temperature. Proc Natl Acad Sci U S A 114:2042-2047. 